\title{
Testing and Validation of the Dynamic Inertia Measurement Method
}

\author{
Alexander W. Chin ${ }^{1}$, Claudia Y. Herrera ${ }^{2}$, and Natalie D. Spivey ${ }^{3}$ \\ NASA Armstrong Flight Research Center \\ P.O. Box 273, Edwards Air Force Base, California 93523 \\ E-mail: alexander.w.chin@nasa.gov, claudia.herrera-1@nasa.gov, natalie.d.spivey@nasa.gov \\ William A. Fladung ${ }^{4}$ and David Cloutier ${ }^{5}$ \\ ATA Engineering, Inc. \\ 13290 Evening Creek Dr. South, Ste. 250, San Diego, California 92128 \\ E-mail: bfladung@ata-e.com, dave.cloutier@ata-e.com
}

\begin{abstract}
The Dynamic Inertia Measurement (DIM) method uses a ground vibration test setup to determine the mass properties of an object using information from frequency response functions. Most conventional mass properties testing involves using spin tables or pendulum-based swing tests, which for large aerospace vehicles becomes increasingly difficult and time-consuming, and therefore expensive, to perform. The DIM method has been validated on small test articles but has not been successfully proven on large aerospace vehicles. In response, the National Aeronautics and Space Administration Armstrong Flight Research Center (Edwards, California) conducted mass properties testing on an "iron bird" test article that is comparable in mass and scale to a fighter-type aircraft. The simple two-I-beam design of the "iron bird" was selected to ensure accurate analytical mass properties. Traditional swing testing was also performed to compare the level of effort, amount of resources, and quality of data with the DIM method. The DIM test showed favorable results for the center of gravity and moments of inertia; however, the products of inertia showed disagreement with analytical predictions.
\end{abstract}

\section{KEYWORDS:}

dynamic inertia measurement

frequency response function

ground vibration test

mass properties

moment of inertia

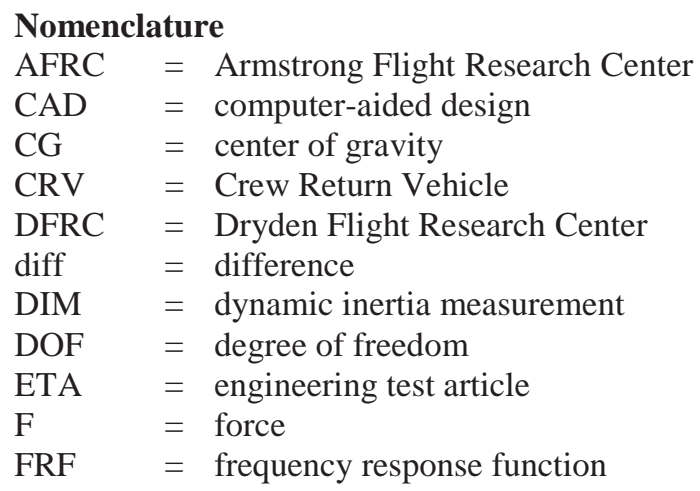

\footnotetext{
${ }^{1}$ Aerospace Engineer

${ }^{2}$ Aerospace Engineer

${ }^{3}$ Aerospace Engineer

${ }^{4}$ Senior Technical Advisor

${ }^{5}$ Project Engineer
} 


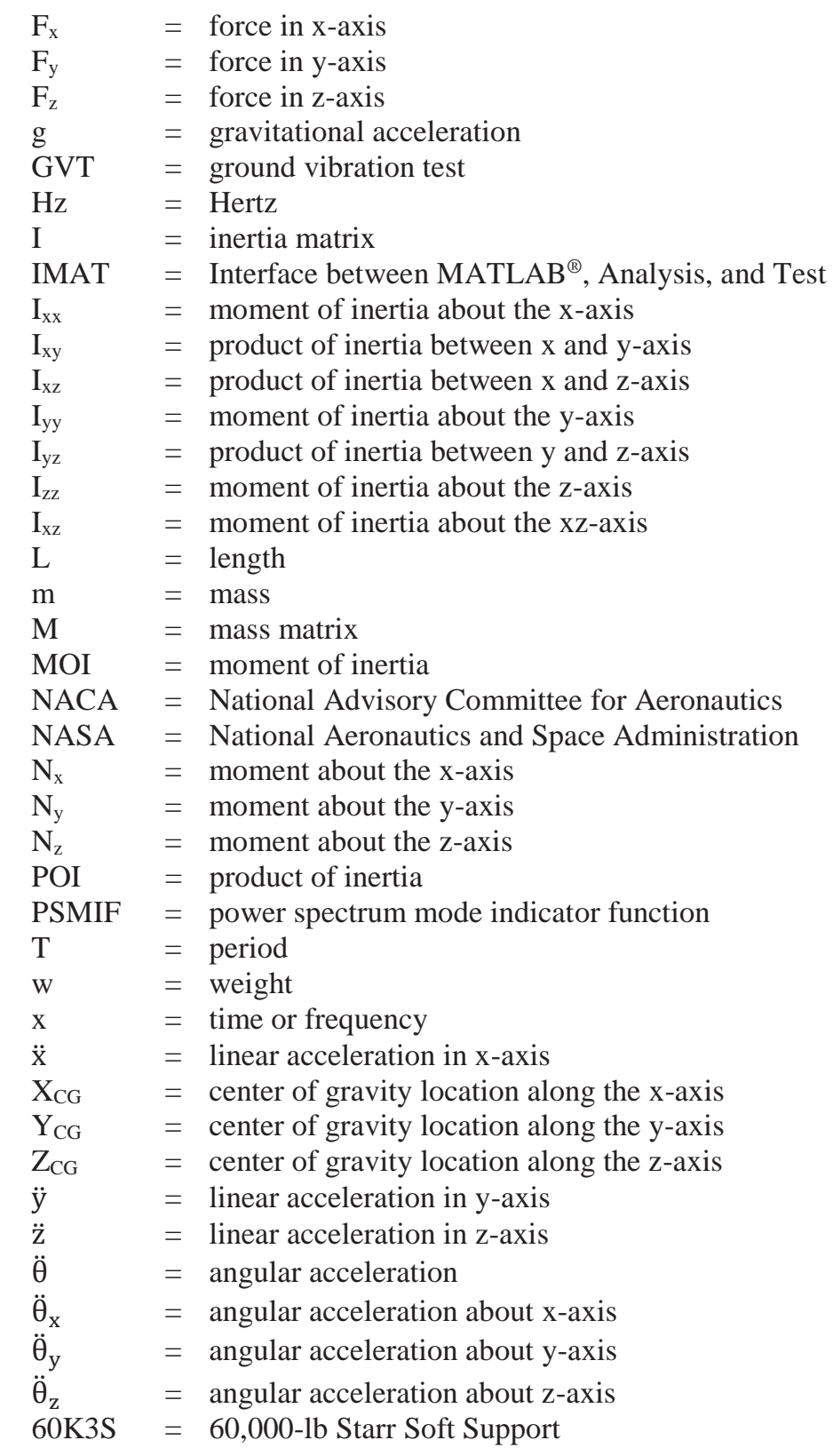

\section{Introduction}

The mass properties of a vehicle include the mass, center of gravity (CG), moments of inertia (MOIs), and products of inertia (POIs). This information is important to understanding and controlling the flight dynamics of the vehicle. The mass and CG can usually be determined through a weight and balance procedure, while MOI and POI require dynamic testing. Analytical models can also provide mass properties information, but must be sufficiently detailed as a realistic representation of the system to be accurate. As examples, vehicle modifications and changes are not always tracked in the computer-aided design (CAD) analytical model; and vehicles can be acquired without their corresponding analytical models. If changes to the vehicle are not explicitly modeled, the analytical mass properties will not be accurate. Remodeling an entire vehicle, however, can be cumbersome and costly to complete. Thus, it becomes necessary to experimentally test for the mass properties of a vehicle.

Spin-balance tables can provide accurate approximations of the CG and MOI, but these become increasingly difficult to use as the size of the object being tested increases. When spin-balance tables are not available or practical, pendulum-based methods are often used; however, pendulum-based methods require significant amounts of labor, materials, and time, leading to high cost and risk. 
Frequency response function (FRF) testing has gained interest as an alternative methodology for determining mass properties using a ground vibration test (GVT) setup. Frequency response function testing analyzes the dynamic response of a test article and is often used to identify mode shapes and natural frequencies of objects. The Dynamic Inertia Measurement (DIM) method utilizes FRF information to determine mass properties.[1]

The DIM method has been in development at the University of Cincinnati and has shown success on a variety of small-scale test articles such as automobile brake rotors, steel blocks, and other custom fixtures from the university.[2,3] Attempts to apply the DIM method to larger test articles, however, have met with limited success.[4] This paper documents efforts to mature the DIM technology for application toward full-scale aerospace vehicles in conjunction with GVTs.

\section{DIM Background Theory}

The mass properties of an object are determined by measuring all forces and moments acting on a body and the rigid body motion caused by these forces and moments. The DIM method measures the inertia properties of an object by analyzing the FRFs measured during a GVT. The FRFs are measurements that normalize the response (acceleration and reaction force) to the excitation force in the frequency domain. A simulated free-free boundary condition GVT provides the appropriate test environment such that all the reaction forces can be measured. The advent of six degree-of-freedom (DOF) force sensors has enabled the measurement of all the reaction forces and moments on the test article. [5,6,7]

The DIM method uses the rigid body forces, moments, and linear and angular accelerations to calculate the inertia matrix. Equation 1 shows Newton's second law simplified for constant mass, which defines the relationship between forces, mass, and linear accelerations.

$$
\{F\}=[M]\{\ddot{x}\}
$$

Equation 2 shows Euler's second law for defining the relationship between moments, moments and products of inertia, and angular accelerations. For this solution, the cross terms were ignored because the test articles are assumed to be rigid to an extent that the vehicle rotation rate terms were small. Note that this assumption would not hold for large, flexible structures.

$$
\{N\}=[I]\{\ddot{\theta}\}
$$

Applying the small angle assumption to the moment arms and combining the force and moment equations for six degrees of freedom yields the 6x6 mass matrix for full rigid body motion as shown in Equation 3. All forces, moments, and accelerations are measured quantities. The forces and moments are measured from DIM-related sensors. The accelerations are measured from GVT sensors. The ten unknown terms in the mass matrix $(\mathrm{M})$ are the mass $(\mathrm{m})$, CG location $\left(\mathrm{X}_{\mathrm{CG}}, \mathrm{Y}_{\mathrm{CG}}, \mathrm{Z}_{\mathrm{CG}}\right)$ with respect to some point $\mathrm{P}$, moments of inertia $\left(\mathrm{I}_{\mathrm{xx}}, \mathrm{I}_{\mathrm{yy}}, \mathrm{I}_{\mathrm{zz}}\right)$ calculated about $\mathrm{P}$, and products of inertia $\left(\mathrm{I}_{\mathrm{xy}}, \mathrm{I}_{\mathrm{xz}}, \mathrm{I}_{\mathrm{yz}}\right)$ calculated about $\mathrm{P}$.

$$
\left\{\begin{array}{c}
\mathrm{F}_{\mathrm{x}} \\
\mathrm{F}_{\mathrm{y}} \\
\mathrm{F}_{\mathrm{z}} \\
\mathrm{N}_{\mathrm{x}} \\
\mathrm{N}_{\mathrm{y}} \\
\mathrm{N}_{\mathrm{z}}
\end{array}\right\}=\left[\begin{array}{cccccc}
\mathrm{m} & 0 & 0 & 0 & \mathrm{mZ}_{\mathrm{CG}} & -\mathrm{mY}_{\mathrm{CG}} \\
0 & \mathrm{~m} & 0 & -\mathrm{mZ}_{\mathrm{CG}} & 0 & \mathrm{mX}_{\mathrm{CG}} \\
0 & 0 & \mathrm{~m} & \mathrm{mY}_{\mathrm{CG}} & -\mathrm{mX}_{\mathrm{CG}} & 0 \\
0 & -\mathrm{mZ}_{\mathrm{CG}} & \mathrm{mY}_{\mathrm{CG}} & \mathrm{I}_{\mathrm{xx}} & -\mathrm{I}_{\mathrm{xy}} & -\mathrm{I}_{\mathrm{xz}} \\
\mathrm{mZ}_{\mathrm{CG}} & 0 & -\mathrm{mX}_{\mathrm{CG}} & -\mathrm{I}_{\mathrm{xy}} & \mathrm{I}_{\mathrm{yy}} & -\mathrm{I}_{\mathrm{yz}} \\
-\mathrm{mY}_{\mathrm{CG}} & \mathrm{mX}_{\mathrm{CG}} & 0 & -\mathrm{I}_{\mathrm{xz}} & -\mathrm{I}_{\mathrm{yz}} & \mathrm{I}_{\mathrm{zz}}
\end{array}\right]\left\{\begin{array}{l}
\ddot{x} \\
\ddot{y} \\
\ddot{z} \\
\ddot{\theta}_{x} \\
\ddot{\theta}_{y} \\
\ddot{\theta}_{\mathrm{z}}
\end{array}\right\}
$$

\section{Previous DIM Validation Efforts on Large-Scale Test Articles}

The National Aeronautics and Space Administration (NASA) Dryden Flight Research Center (DFRC) which was recently renamed to the NASA Armstrong Flight Research Center (AFRC) attempted to apply the DIM method on two large-scale test articles. The first test article was the X-38 Crew Return Vehicle (CRV); the second test article was an assembly of steel I-beams and plates referred to as the "initial iron bird."

\subsection{X-38 Crew Return Vehicle}

In the late 1990s NASA DFRC researchers applied the DIM two separate times on the X-38 CRV. Challenges arose due to flexible modes of internal vehicle components. Although the DIM technology clearly required further maturation, the results compared favorably with those obtained through experimental testing. Figure 1 shows the X-38 CRV undergoing DIM testing. 


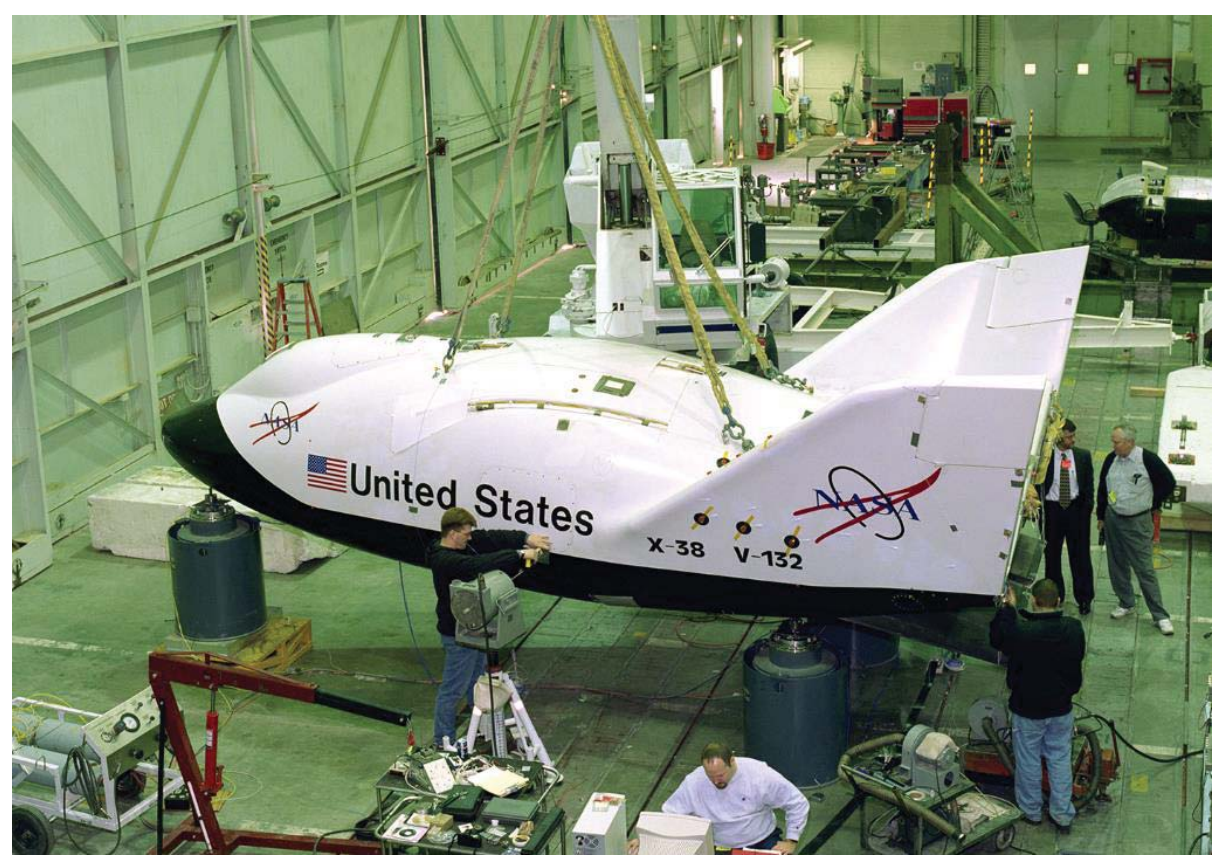

Figure 1. The X-38 CRV undergoing DIM testing.

\subsection{Initial Iron Bird Test Article}

During the summer of 2010, an experiment the sole purpose of which was to validate the DIM method for large-scale vehicles was conducted at the NASA DFRC. The test article was an iron bird assembled from an assortment of welded steel beams and plates and referred to as the initial iron bird.

This testing effort supported the procurement of the specialized instrumentation needed to perform the DIM test and the development of the DIM processing algorithms.

A laser tracker was used for precise measurements of the locations and orientations of the sensors. Several sets of GVT accelerometers were installed and multiple test conditions were performed. Some problems were experienced during the test and analysis. In order to interface the initial iron bird to the soft supports, steel pedestals were inserted between the soft supports and the initial iron bird, because of soft-support extension limits. The pedestals and soft supports introduced local modes that limited the frequency range at which the DIM method could be applied and analyzed. In addition, the initial iron bird was not ideal for highly accurate analytical mass property predictions because it consisted of an assortment of welded plates having various holes.

The results of the effort were mixed, with several lessons learned to improve the validation effort. The biggest problems to correct included avoiding the appearance of local modes and creating an experimental test article to yield high confidence in its analytical mass properties. Figure 2 shows the DIM test setup from the initial iron bird test article. 


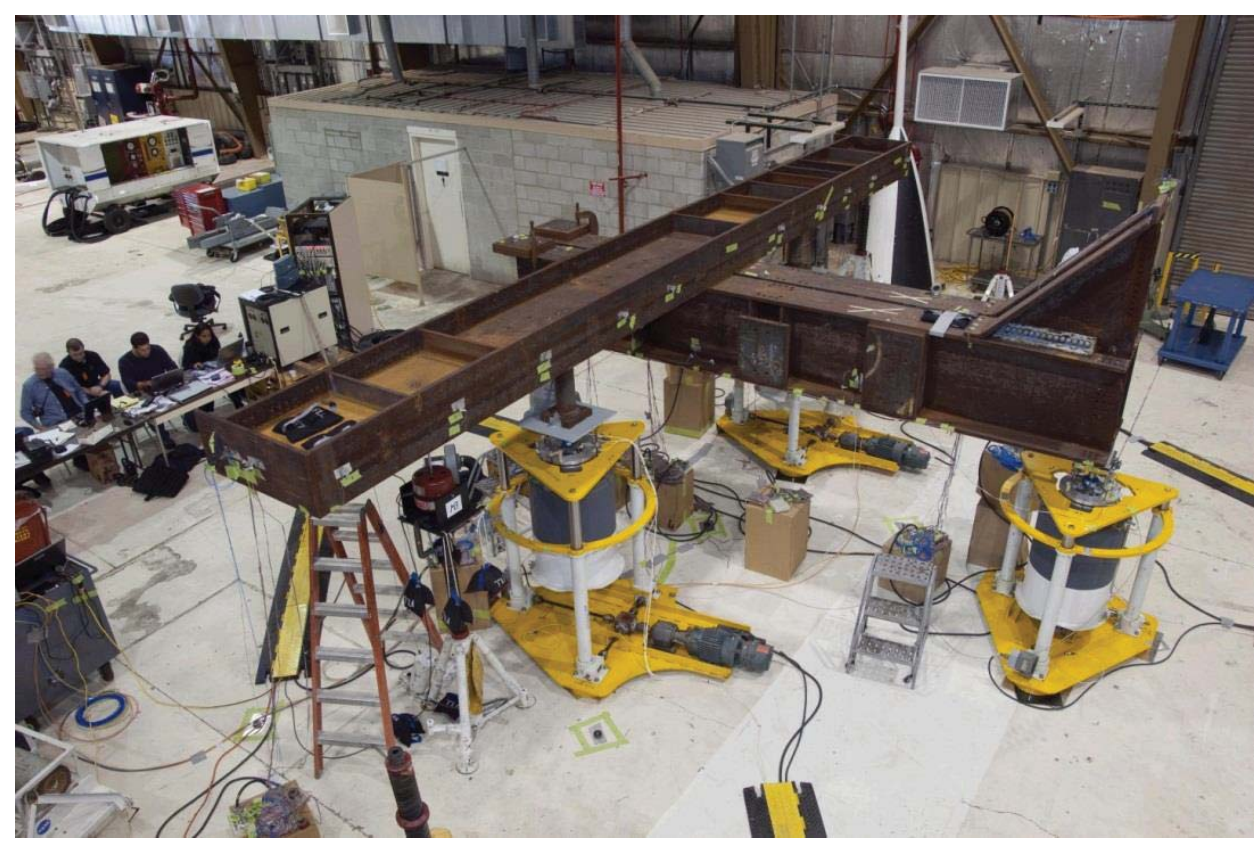

Figure 2. The initial iron bird test article undergoing DIM testing.

\section{Iron Bird Test Article}

Two 8500-lb, 20-ft long, W14X426 steel I-beams were bolted together off-center to model the approximate mass of a fighter-type aircraft. The test article which was dubbed the "iron bird;" is shown in Figure 3. The iron bird was intentionally simple in design to ensure high reliability of its analytical mass properties. Holes were drilled into the iron bird at designated locations to attach interface ball plates that were to rest on aircraft jacks and the soft-support system. Holes were also drilled to attach any required fixture(s) for MOI pendulum testing. Steel was chosen for its rigidity and lower cost.

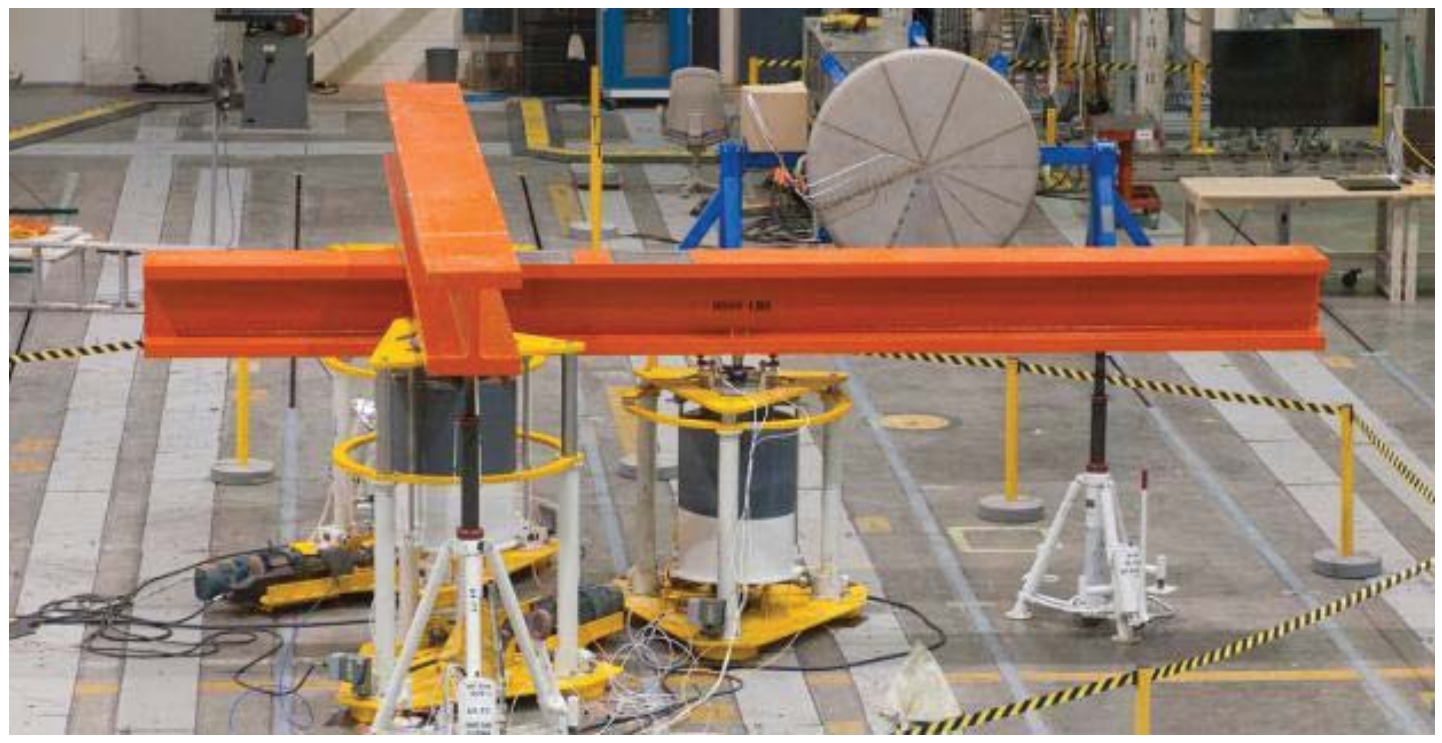

Figure 3. The iron bird test article.

The reference coordinate system used for the iron bird places the origin at the forward lower surface of the test article. Positive $\mathrm{X}$ points aft from the nose, positive $\mathrm{Y}$ points in the direction of the right wing, and positive $\mathrm{Z}$ points upward on the test article. The coordinate system is defined in the CAD model shown in Figure 4. 


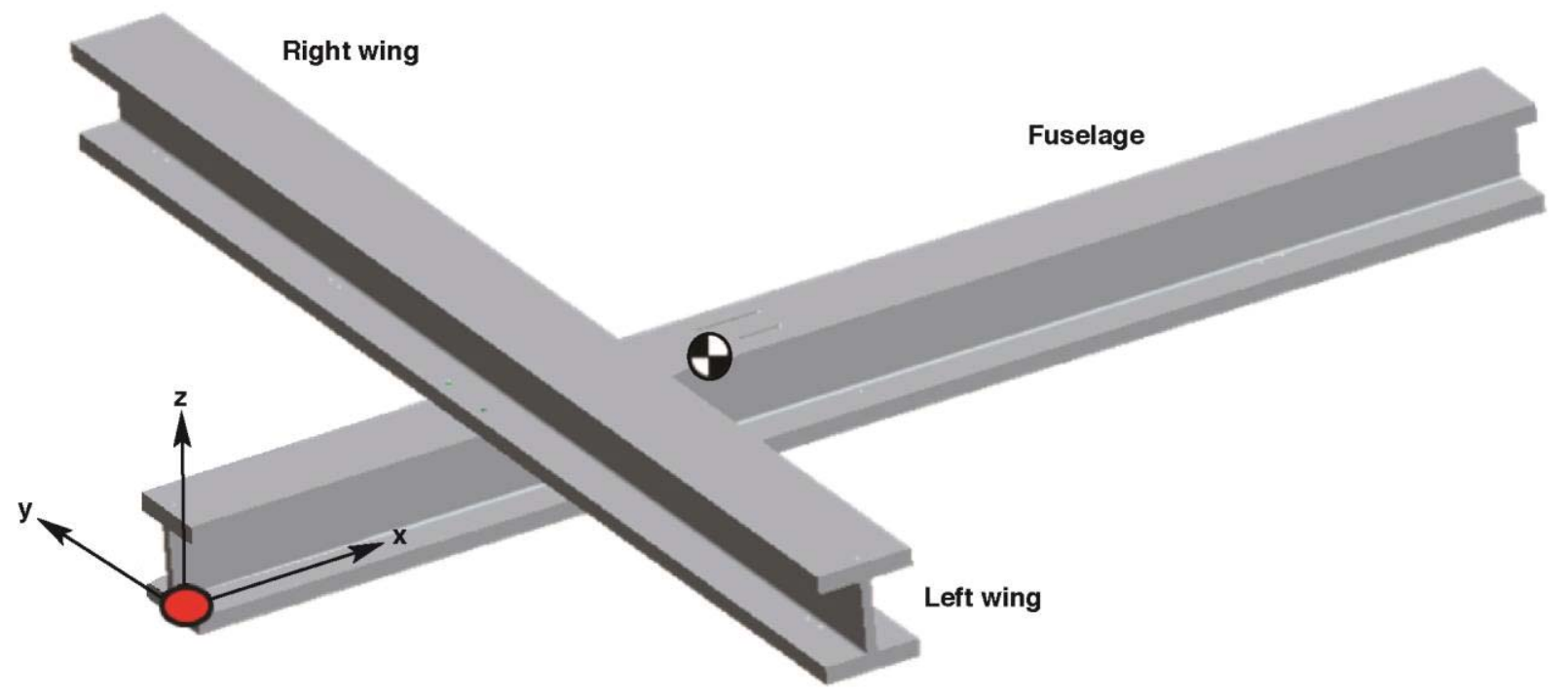

Figure 4. The CAD model showing the coordinate system for the iron bird.

\section{Test Plan}

Three methods for determining the mass properties of the 17,000-lb iron bird test article were used for comparison. First, an analytical model was created using the solid modeling CAD program PTC Creo (Pro/ENGINEER ${ }^{\circledR}$ ) (PTC Inc., Needham, Massachusetts). Second, pendulum swing tests were performed. Third, the DIM method was implemented. These three separate and independent approaches were used to document the level of effort involved for each method. For expediency, however, the pendulum swing tests relied on the analytical vertical $Z_{\text {CG }}$. The DIM test obtained data completely independently of any analytical and pendulum mass properties data.

\section{Analytic Model}

Pro/ENGINEER ${ }^{\circledR}$ was used to analytically model the iron bird test article and obtain the mass properties. Care was taken to apply as many realistic details to the CAD model as possible, including all holes and added interface attachments. The simplicity of the iron bird test article design was to ensure the analytical CAD model could be treated as the truth model. Table 1 shows the CAD model analytic mass properties of the iron bird.

Table 1. The CAD model analytical mass properties of the iron bird.

\begin{tabular}{|c|c|c|c|c|c|c|c|c|c|}
\hline Mass, $\mathrm{kg}$ & $\mathrm{X}_{\mathrm{CG}} \mathrm{m}$ & $\mathrm{Y}_{\mathrm{CG}} \mathrm{m}$ & $\mathrm{Z}_{\mathrm{CG}} \mathrm{m}$ & $\begin{array}{c}\mathrm{I}_{\mathrm{xx}}, \\
\mathrm{kg} \mathrm{m}^{2}\end{array}$ & $\begin{array}{c}\mathrm{I}_{\mathrm{yy}}, \\
\mathrm{kg} \mathrm{m}^{2}\end{array}$ & $\begin{array}{c}\mathrm{I}_{\mathrm{zz}}, \\
\mathrm{kg}^{*} \mathrm{~m}^{2}\end{array}$ & $\begin{array}{c}\mathrm{I}_{\mathrm{xy}}, \\
\mathrm{kg} \mathrm{m}^{*}\end{array}$ & $\begin{array}{c}\mathrm{I}_{\mathrm{xz}}, \\
\left(\mathrm{kg}^{*} \mathrm{~m}^{2}\right)\end{array}$ & $\begin{array}{c}\mathrm{I}_{\mathrm{yz}}, \\
\mathrm{kg}^{*} \mathrm{~m}^{2}\end{array}$ \\
\hline 7716.5 & 2.3 & 0.0 & 0.5 & 12700.6 & 17207.2 & 28503.1 & 0.0 & -1398.8 & 0.0 \\
\hline
\end{tabular}

\section{Pendulum Swing Test}

Weight and balance measurements in conjunction with pendulum swing tests have been the conventional experimental method for obtaining mass properties of aerospace vehicles for almost a century. This analytically straightforward method focuses on measuring weight, periods, and pendulum lengths. Many problems can develop, however, when trying to meet the requirements for a successful test. The stiffness and integrity of the lifting hardware must be certified for NASA or any other lifting operations. In addition, the pendulum test hardware must be nearly frictionless to ensure minimal damping for accurate pendulum period measurements.

The $\mathrm{X}_{\mathrm{CG}}$ and $\mathrm{Y}_{\mathrm{CG}}$ were measured using a balance of forces calculation. The $\mathrm{Z}_{\mathrm{CG}}$ was not experimentally verified due to the level of effort required to tilt the iron bird at multiple angles for $Z_{\mathrm{CG}}$ calculation. The experimentally-measured weight, $\mathrm{X}_{\mathrm{CG}}$, and $\mathrm{Y}_{\mathrm{CG}}$ are shown in Table 2. Uncertainties were calculated using the law of propagation of uncertainty methodology. 
Table 2. Experimental weight, $\mathrm{X}_{\mathrm{CG}}$, and $\mathrm{Y}_{\mathrm{CG}}$

\begin{tabular}{|l|c|c|c|c|}
\cline { 2 - 5 } \multicolumn{1}{c|}{} & Measured & Analytic & Diff analytic, \% & Uncertainty \\
\hline Mass, kg & 7698.8 & 7716.5 & -0.23 & $+/-47.36$ \\
\hline $\mathrm{X}_{\mathrm{CG}}, \mathrm{m}$ & 2.286 & 2.286 & 0.00 & $+/-2.09 \times 10^{-3}$ \\
\hline $\mathrm{Y}_{\mathrm{CG}}(\mathrm{m})$ & -0.000762 & 0 & $\mathrm{n} / \mathrm{a}$ & $+/-2.07 \times 10^{-3}$ \\
\hline
\end{tabular}

Classical pendulum equations were used to determine the moments of inertia. The methodology and equations referenced multiple National Advisory Committee for Aeronautics (NACA) papers.[8,9,10,11,12,13] In order to obtain the moments of inertia of the iron bird, all tests also required swinging the fixture by itself in order to subtract out the fixture mass properties from the total combined iron bird and fixture assembly. The moments of inertia about the x-axis and y-axis used a compound pendulum setup and is calculated from Equation 4, where terms with a subscript of " 1 " represent the combined test article and fixture; terms with a subscript of " 2 " represent the fixture only; and " $L$ " is the length from the pivot point to the CG of the respective subscripts.

$$
\mathrm{I}_{\mathrm{xx} \text { ETA }}=\left[\frac{\mathrm{w}_{1} \mathrm{~T}_{1}{ }^{2} \mathrm{~L}_{1}}{4 \pi^{2}}-\frac{\mathrm{w}_{1} \mathrm{~L}_{1}{ }^{2}}{\mathrm{~g}}\right]-\left[\frac{\mathrm{w}_{2} \mathrm{~T}_{2}{ }^{2} \mathrm{~L}_{2}}{4 \pi^{2}}-\frac{\mathrm{w}_{2} \mathrm{~L}_{2}{ }^{2}}{\mathrm{~g}}\right]
$$

The z-axis MOI uses a bifilar torsional pendulum setup and is calculated from Equation 5. The "L" term is the suspended length from the pivot point.

$$
\mathrm{I}_{\mathrm{zz} \mathrm{ETA}}=\frac{\mathrm{T}_{1}^{2} \mathrm{w}_{1} \mathrm{~A}^{2}}{16 \pi^{2} \mathrm{~L}}-\frac{\mathrm{T}_{2}{ }^{2} \mathrm{w}_{2} \mathrm{~A}^{2}}{16 \pi^{2} \mathrm{~L}}
$$

Figure 5 shows the iron bird test article undergoing $\mathrm{I}_{\mathrm{xx}}$ pendulum testing.

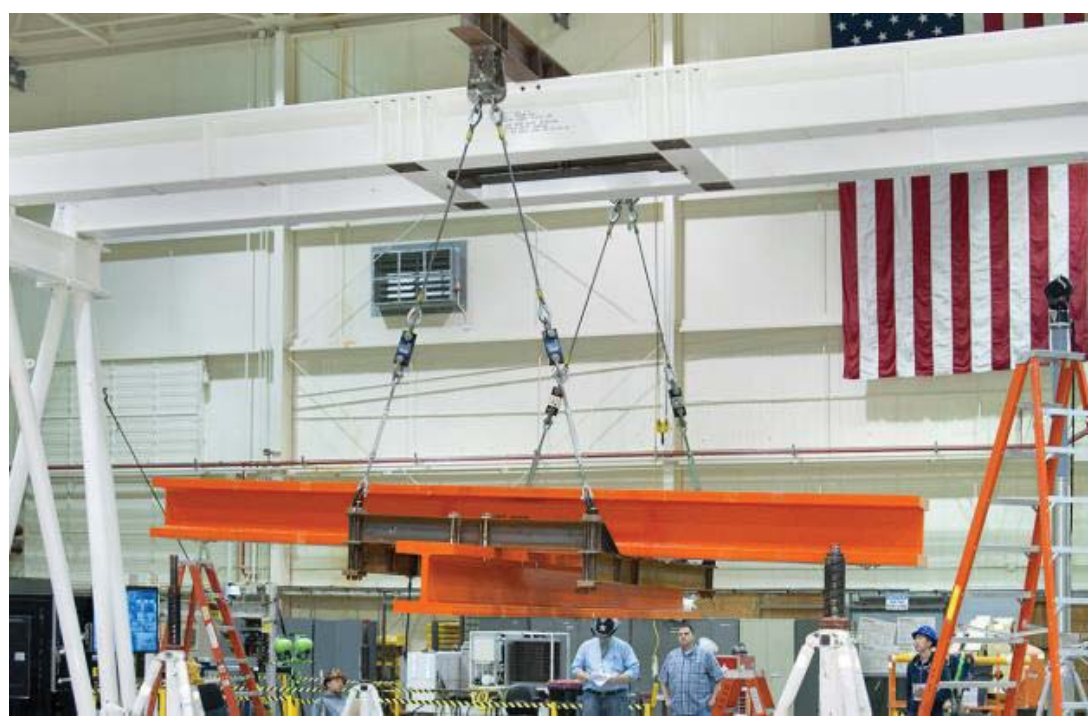

Figure 5. The iron bird undergoing $\mathrm{I}_{\mathrm{xx}}$ pendulum testing.

Figure 6 shows the iron bird test article undergoing $\mathrm{I}_{\mathrm{zz}}$ pendulum testing. 


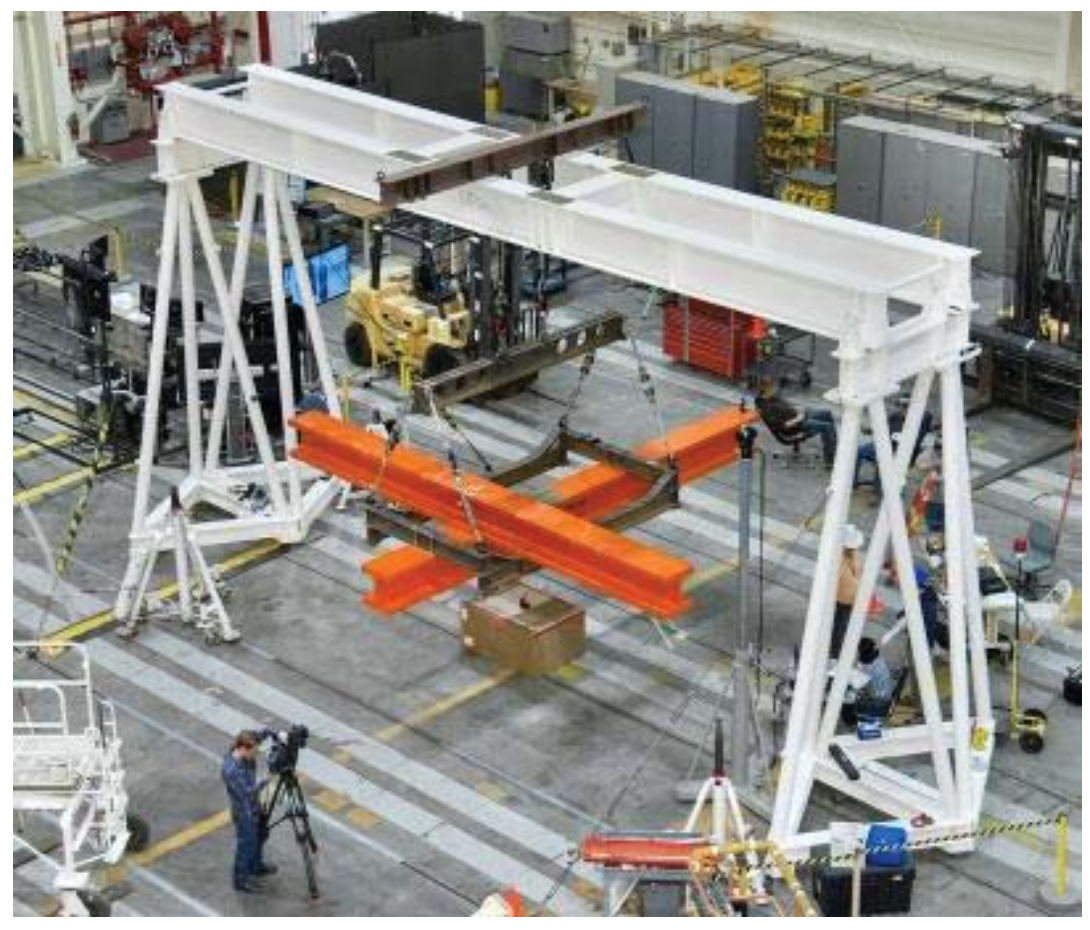

Figure 6. The iron bird undergoing $\mathrm{I}_{\mathrm{zz}}$ pendulum testing.

Obtaining the product of inertia, $\mathrm{I}_{\mathrm{xz}}$, required the iron bird to rotate in the bifilar pendulum in a tilted pitch configuration. Due to limitations of the test setup, only a tilt of 5 deg was achievable, instead of the minimum 15 deg needed. This condition led to a large $\mathrm{I}_{\mathrm{xz}}$ error compared to the analytical predictions. The results of the iron bird MOI and POI are summarized in Table 3 . The large $\mathrm{I}_{\mathrm{xz}}$ uncertainty comes from compounding uncertainties from $\mathrm{I}_{\mathrm{xx}}$ and $\mathrm{I}_{\mathrm{zz}}$ measurements. A small tilt angle exacerbates the uncertainty as well.

Table 3. Summary of iron bird pendulum MOI results.

\begin{tabular}{|l|c|c|c|c|}
\hline & $\begin{array}{c}\text { Measured MOI, } \\
\mathrm{kg}^{*} \mathrm{~m}^{2}\end{array}$ & $\begin{array}{c}\text { Analytic MOI, } \\
\mathrm{kg}^{*} \mathrm{~m}^{2}\end{array}$ & Diff analytic, \% & Uncertainty, \% \\
\hline $\mathrm{I}_{\mathrm{xx}}$ iron bird & 12,265 & 12,708 & -3 & 8 \\
\hline $\mathrm{I}_{\mathrm{yy}}$ iron bird & 17,932 & 17,196 & 4 & 10 \\
\hline $\mathrm{I}_{\mathrm{zz}}$ iron bird & 27,848 & 28,507 & -2 & 3.40 \\
\hline $\mathrm{I}_{\mathrm{xz}}$ iron bird & $-2,767$ & $-1,398$ & 98 & 242.70 \\
\hline
\end{tabular}

Several difficulties with the test setup and the data were encountered using the pendulum method. Weight exceeding safety close calls was an ever-present concern. Oscillations damped out more quickly than was expected and the frequency oscillation was not constant. Post-test analysis revealed that the main culprit for the observed frequency changes was the non-ideal design of the pendulum test hardware.

\section{Dynamic Inertia Measurement Test}

The iron bird DIM testing was conducted at the NASA AFRC Flight Loads Laboratory (FLL) from September 16, 2013 through September 24, 2013. ATA Engineering, Inc. (San Diego, California) was contracted to assist with the iron bird DIM testing and to perform analysis of the data, in order to utilize their previous experience with the DIM method.[14,15] The equipment required and test description required for the DIM method test is described below.

\subsection{Equipment}

The DIM method requires many of the same sensors (accelerometers, force transducers, and soft-support load cells) and equipment (shakers, soft-support system) that are needed to perform a GVT. In addition to the GVT equipment, a few specialized sensors, such as 6-DOF force sensors, 3-DOF force transducers, laser tracker, and seismic accelerometers, are 
required for DIM. The 6-DOF force sensors ensure all reaction forces and moments needed for the DIM calculation are measured. The seismic accelerometers have a higher sensitivity and lower noise floor which may be needed to accurately record low-amplitude responses. The DIM processing will evaluate and compare the need for the seismic accelerometers versus typical GVT accelerometers. A data acquisition system was used to acquire and record data from all the sensors installed during DIM testing. Each sensor location and orientation was measured with a laser tracker.

\subsubsection{Soft-Support System}

The 60,000-lb Starr Soft Support (60K3S) system is a specialized piece of equipment that acts as both an aircraft jack and a nitrogen bladder soft-support system. The soft suspension system was used to support the iron bird in order to simulate free-free boundary conditions as accurately as possible. The soft-support isolation system consists of an aircraft-jacking device with three jacking points, each point having an individual motor and accommodating up to 20,000 lb, for a total capacity of 60,000 lb. The 60K3S system can be transported to an aircraft by forklift and placed at the jacking points using a pallet jack. The motors power the electric actuators, raising the aircraft off the ground until the landing gear can retract.[16]

\subsubsection{3-DOF Load Cells: Soft Supports}

On each of the soft supports, a 3-DOF load cell (Interface 5200 series) (Interface Inc., Scottsdale, Arizona) was used to monitor the 60K3S side loads and ensure that load limits were not exceeded. This information was not used in the DIM calculation. These load cells are part of the standard instrumentation for using the soft supports for GVTs. The 3-DOF 60K3S load cells are shown in Figure 7.

\subsubsection{6-DOF Force Sensors: Reaction Forces}

Three 6-DOF force sensors were custom-made for the NASA AFRC researchers by PCB Piezotronics, Inc. (Depew, New York). These unique sensors are an assembly of three 3-DOF piezoelectric dynamic force sensors. The load cells were placed between the iron bird and the soft-support system. The 6-DOF force sensors are shown in Figure 7.
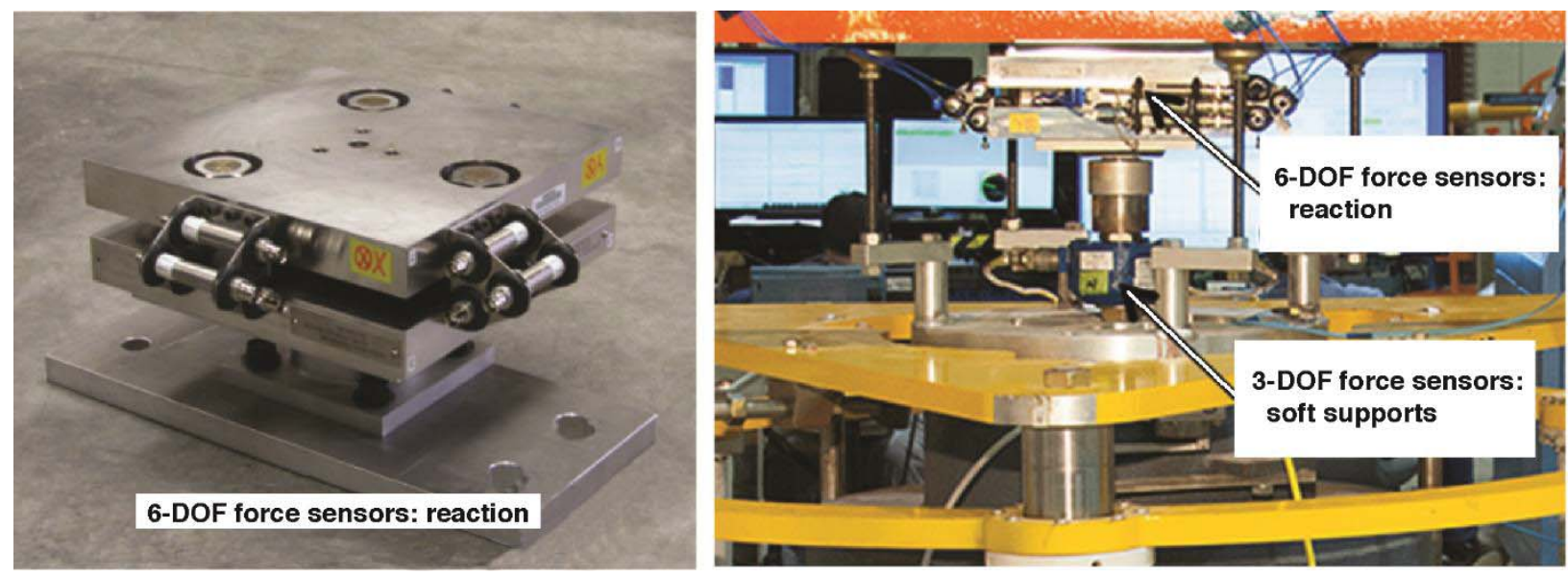

Figure 7. Left, the 6-DOF reaction force sensor; and right, the 3-DOF soft support load cell.

\subsubsection{Shakers: Excitation}

The DIM testing required up to two shakers for excitation during random and sine-sweep test runs. For all configurations, either one or two 110-lb MB Dynamics (Cleveland, Ohio) electrodynamic shakers were used to excite the structure. The shakers used plastic stingers to transmit a direct force with minimal bending moment. The stingers are rigid enough to transmit unattenuated axial force within the frequency range of interest. The stingers completed the connections between the force transducer and shakers. For tests runs using two shakers, the shakers were attached to the structure at a skewed angle. Shaker blocks with a 45-deg angle were attached to the structure, and then the force transducer was attached to the angled side of the block. A picture of a shaker is shown in Figure 8. 


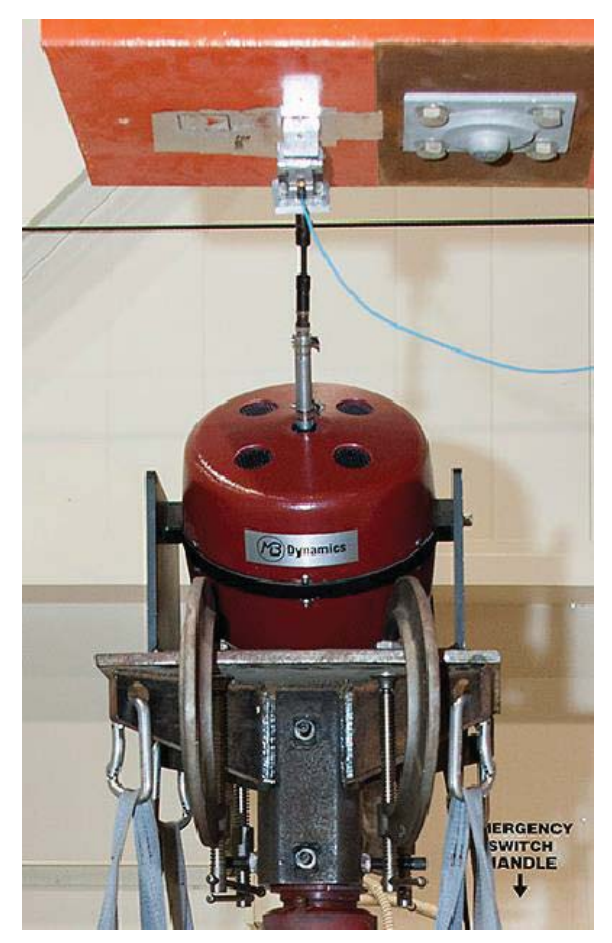

Figure 8. An MB Dynamics (Cleveland, Ohio) shaker.

\subsubsection{3-DOF and 1-DOF Force Sensors: Excitation}

A 3-DOF excitation force sensor (PCB M/N 261A01) (PCB Piezotronics, Inc.) was used to measure the input force from the shaker. Only the force in-line with the shaker was used as the reference for the FRF measurements. The forces in the other two axes were treated as reaction forces. The transverse forces were typically only a few percent of the in-line force. A 3-DOF excitation force sensor is shown in Figure 9.

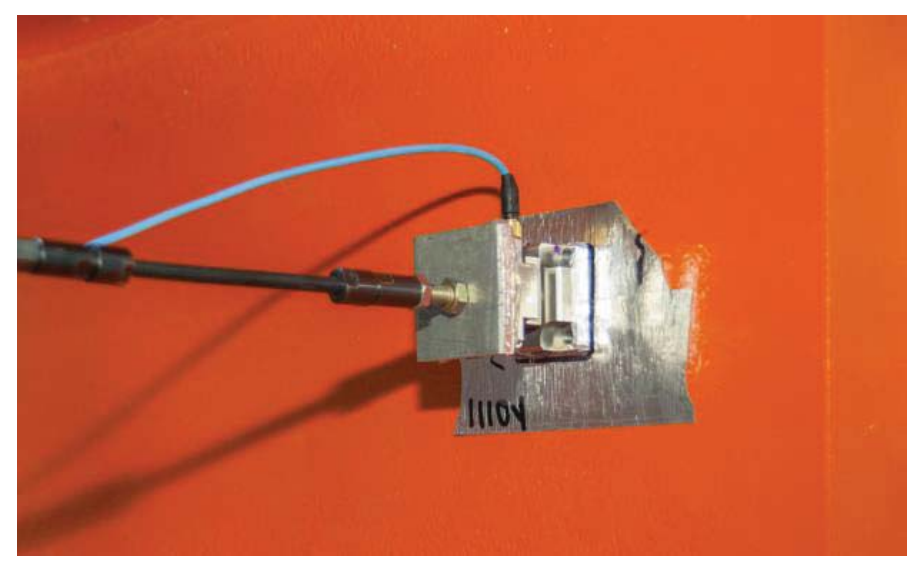

Figure 9. A 3-DOF excitation force transducer.

\subsubsection{Accelerometers}

Three sets of accelerometers were installed for the DIM test: seismic accelerometers, single-axis accelerometers, and triaxial accelerometers. The primary set of DIM accelerometers consisted of single-axis seismic accelerometers (PCB M/N 393B04) (PCB Piezotrinics, Inc.) mounted in a triaxial configuration. These transducers were selected for their high sensitivity, low noise floor, and low-frequency characteristics to evaluate the necessity to capture acceleration for more massive objects. The second set consisted of single-axis 100mV/g accelerometers (PCB M/N T333B) (PCB Piezotronics, Inc.) typically used for modal tests, which were also mounted in a triaxial configuration collocated with the seismic accelerometers. The purpose of this redundancy was to compare the DIM processing results between these two types of sensors and evaluate the adequacy of 
typical modal accelerometers versus the expensive seismic accelerometers. The third set consisted of $100 \mathrm{mV} / \mathrm{g}$ triaxial accelerometers (PCB M/N 356A16) (PCB Piezotronics, Inc.) mounted on the wings, fuselage, and soft supports for modal information. The first two sets of accelerometers installed for the DIM test were defined using a local Cartesian coordinate system aligned with the global Cartesian coordinate system. The third set was installed in the global Cartesian coordinate system for modal situational awareness and not used in the DIM calculation. A laser tracker system was used to determine the accelerometer locations. Figure 10 shows the three seismic and three T333B (PCB Piezotronics, Inc.) single-axis accelerometers, mounted in a triaxial configuration, and the triaxial accelerometers.
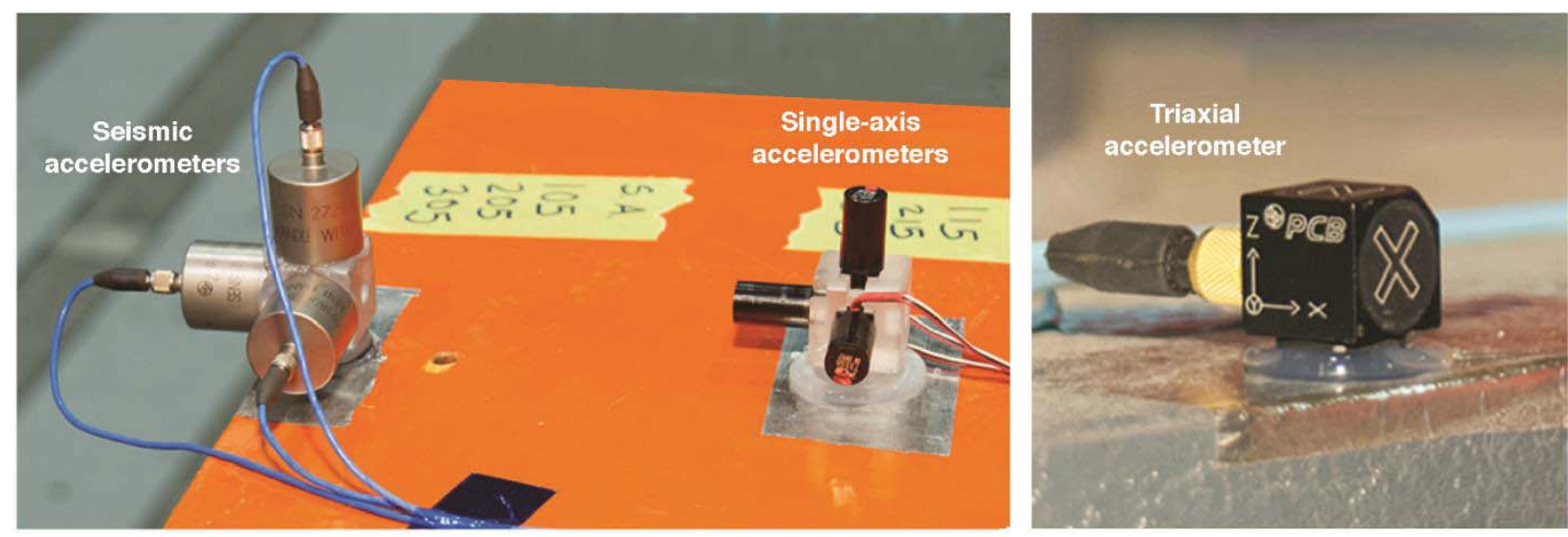

Figure 10. Left, the three seismic and three single-axis accelerometers; and right the triaxial accelerometer.

\subsubsection{Laser Tracker System}

The DIM method involves resolving the measured DOFs to rigid body accelerations and forces at a single point. Performing this resolution requires the accurate position and orientation of the measured accelerations, excitation forces, and reaction forces. In the most general sense, a procedure was developed to create a local coordinate system at each measurement node with respect to the global coordinate system for all of the DIM sensors of interest. The NASA AFRC has a laser tracker system that can accurately and precisely measure the coordinates of a point in space. This system was used to measure the accelerometers, 6-DOF force sensors, and force transducers using a custom tool designed to capture three points relative to a corner of the sensor to be measured, as shown in Figure 11. The output text file from the laser tracker software was then used to automatically generate an MSC Nastran (MSC.Software Corporation, Newport Beach, California) bulk data file, and the output of the Nastran run provided the transformation matrices from the measurement DOFs to the rigid body node. This method decreased the possibility of errors due to misalignment and facilitated the bookkeeping of the sensor local coordinate systems.

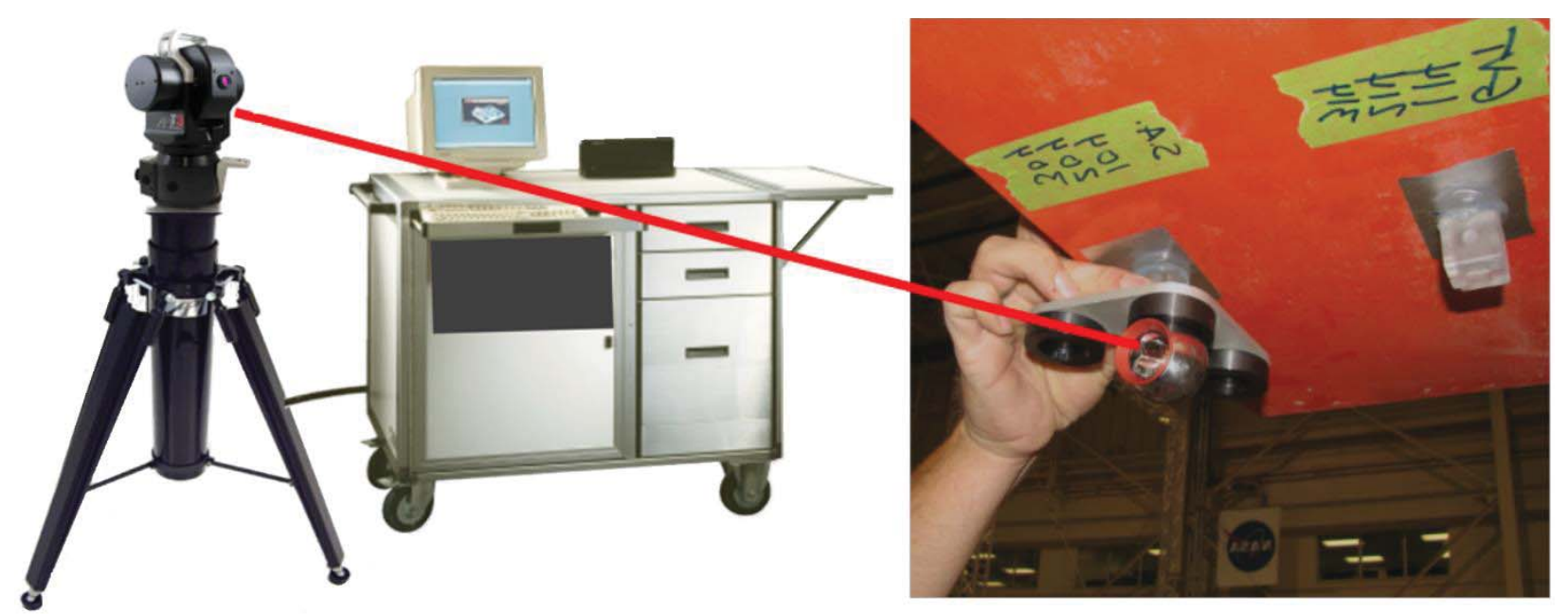

Figure 11. The laser tracker system for sensor locations. 


\subsection{Test Model}

The final set of accelerometers totaled 144 DOFs at 51 different node locations. Even though all test DOFs were nominally coincident with the global Cartesian coordinate system, a laser tracker was used to precisely define a local displacement coordinate system for each sensor location used for the DIM calculations. The laser tracker was used to define local displacement coordinate systems for the collocated DIM accelerometers (seismic and T333B) (PCB Piezotronics, Inc.), the 3-DOF force transducer and the 6-DOF reaction force sensors. The DOFs for the test article and soft-support system sensor locations which were not used in the DIM calculations were measured by the laser tracker but were defined in the global coordinate system. Figure 12 shows the test display model and accelerometer locations. Each arrow in the figure represents the DOFs at an accelerometer location. The blue elements represent the three instrumented soft supports.

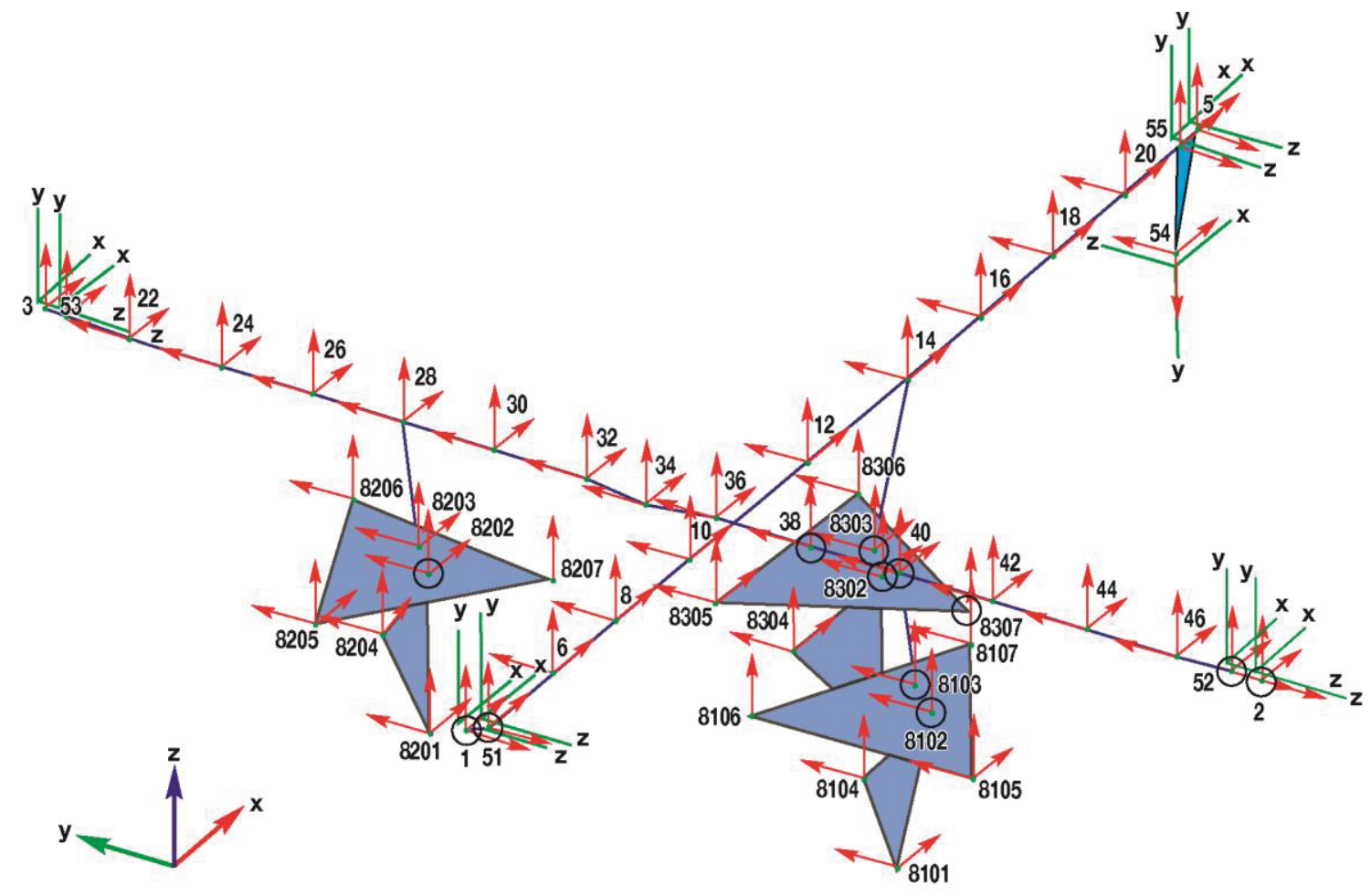

Figure 12. The test display model and accelerometer locations.

\subsection{Test Description}

A total of twelve different DIM analysis cases were conducted through the course of 54 test runs. These runs included check-out, single-shaker, multi-shaker, and quiescent runs.

During preliminary test runs, unexpected soft-support modes in the frequency range of 6 to $14 \mathrm{~Hz}$ were observed. Additional accelerometers were installed on the 60K3S to characterize these modes. Based on the observed mode shapes, the lower portion of the soft support was constrained to the supporting frame before testing was resumed.

The added constraints to the 60K3S increased the stiffness, and the 60K3S modes moved from the frequency range of 6 to $14 \mathrm{~Hz}$ to the frequency range of 10 to $18 \mathrm{~Hz}$ to aid in the frequency separation necessary for the DIM calculation. The power spectrum mode indicator functions (PSMIFs), a summation of the squared-magnitude of the FRF, plotted in Figure 13 show the effect of the added constraints with the original PSMIF (solid blue) compared to the modified PSMIF (dashed blue). The other PSMIF lines were taken at the start of each testing day to verify that the 60K3S modes were still beyond the $10 \mathrm{~Hz}$ range. 


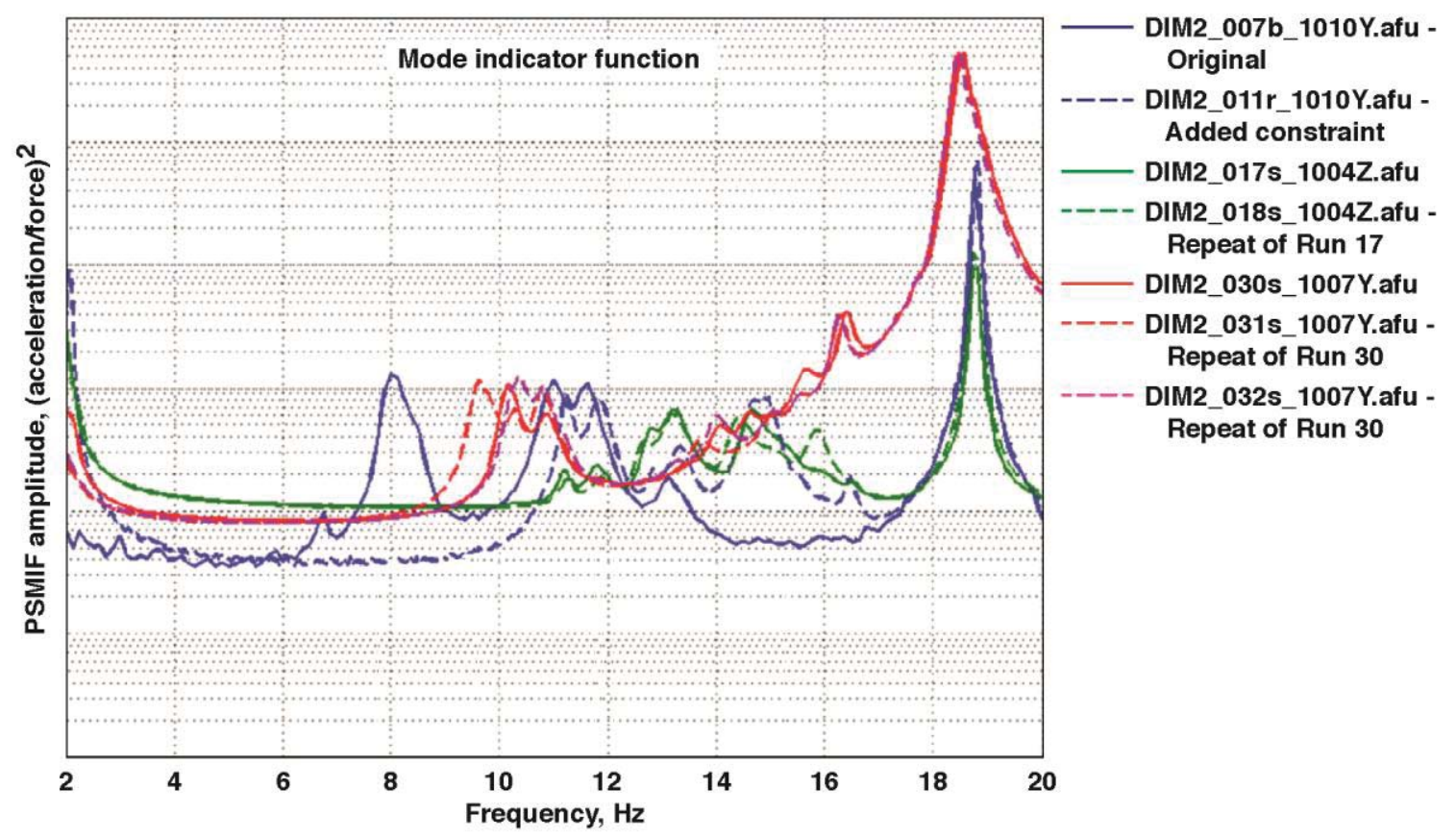

Figure 13. Power spectrum mode indicator functions showing the effect of added constraints on the 60K3S.

For reference, modes extracted from the multiple-shaker random run (run 43) are provided in Table 4. All six iron bird rigid body modes were extracted and were at less than $2 \mathrm{~Hz}$. The first set of 60K3S modes were in the frequency range of 10 to $18 \mathrm{~Hz}$. The first flexible mode of the iron bird was at $18.7 \mathrm{~Hz}$.

Table 4. Modes extracted from the multiple-shaker random run of the iron bird.

\begin{tabular}{|l|c|c|l|}
\hline Mode & Frequency, Hz & $\begin{array}{c}\text { Damping, \% } \\
\text { critical }\end{array}$ & Description \\
\hline 1 & 0.72 & 8.52 & Rigid body pitch \\
\hline 2 & 0.98 & 6.32 & Rigid body roll \\
\hline 3 & 1.25 & 3.81 & Rigid body yaw \\
\hline 4 & 1.56 & 6.21 & Rigid body vertical \\
\hline 5 & 1.80 & 2.99 & Rigid body fore-aft \\
\hline 6 & 1.99 & 2.91 & Rigid body lateral \\
\hline 7 & 10.08 & 1.99 & Starboard 60K3S canister $\mathrm{X}+/ \mathrm{Y}-$ \\
\hline 8 & 11.13 & 1.27 & Port 60K3S canister $\mathrm{X}+/ \mathrm{Y}-$ \\
\hline 9 & 11.47 & 1.46 & Starboard 60K3S canister $\mathrm{X}+/ \mathrm{Y}+$ \\
\hline 10 & 12.41 & 0.98 & Aft 60K3S canister RZ \\
\hline 11 & 12.96 & 1.77 & Aft 60K3S canister $\mathrm{X}+/ \mathrm{Y}-$ \\
\hline 12 & 13.78 & 1.27 & Aft 60K3S canister $\mathrm{X}+/ \mathrm{Y}+$ \\
\hline 13 & 13.79 & 1.52 & Starboard 60K3S $\mathrm{X}+/ \mathrm{Y}-$ \\
\hline 14 & 14.88 & 1.00 & Port 60K3S X+/Y+ \\
\hline 15 & 15.61 & 1.07 & Starboard 60K3S $\mathrm{X}+\mathrm{Y}+$ \\
\hline 16 & 16.37 & 0.72 & Port 60K3S lateral \\
\hline 17 & 18.23 & 2.03 & Aft 60K3S lateral \\
\hline 18 & 18.73 & 0.24 & Iron bird first flexible mode \\
\hline
\end{tabular}


Several parameters during the DIM testing were changed to evaluate and compare the results of the DIM calculations to determine which parameters worked well and which did not. Each DIM analysis case consisted of two or more test runs. Several types of shaker excitation were used for the DIM testing: single-shaker and multiple-shaker burst random, true random, and sine-sweep excitation. The shakers were also placed at various locations (nose, right wing, left wing, and tail) around the test article to determine the ideal excitation locations for the DIM calculation. The list of cases is shown in Table 5.

Table 5. Dynamic Inertia Method analysis cases.

\begin{tabular}{|l|l|l|l|}
\hline $\begin{array}{l}\text { Analysis } \\
\text { case }\end{array}$ & $\begin{array}{l}\text { Shaker } \\
\text { configuration }\end{array}$ & Shaker excitation & Accelerometers \\
\hline 1 & Single & Random $(0$ to $100 \mathrm{~Hz})$ & Seismic \\
\hline 2 & Single & Random $(0$ to $12 \mathrm{~Hz})$ & Seismic \\
\hline 3 & Single & Sine sweep $(1$ to $20 \mathrm{~Hz})$ & Seismic \\
\hline 4 & Single & Random $(0$ to $100 \mathrm{~Hz})$ & GVT \\
\hline 5 & Single & Random $(0$ to $12 \mathrm{~Hz})$ & GVT \\
\hline 6 & Single & Sine sweep $(1$ to $20 \mathrm{~Hz})$ & GVT \\
\hline 7 & Double & Random $(0$ to $100 \mathrm{~Hz})$ & Seismic \\
\hline 8 & Double & Random $(0$ to $12 \mathrm{~Hz})$ & Seismic \\
\hline 9 & Double & Sine sweep $(1$ to $20 \mathrm{~Hz})$ & Seismic \\
\hline 10 & Double & Random $(0$ to $100 \mathrm{~Hz})$ & GVT \\
\hline 11 & Double & Random $(0$ to $12 \mathrm{~Hz})$ & GVT \\
\hline 12 & Double & Sine sweep $(1$ to $20 \mathrm{~Hz})$ & GVT \\
\hline
\end{tabular}

Figure 14 shows the iron bird test article undergoing DIM testing on soft supports with two shakers for excitation.

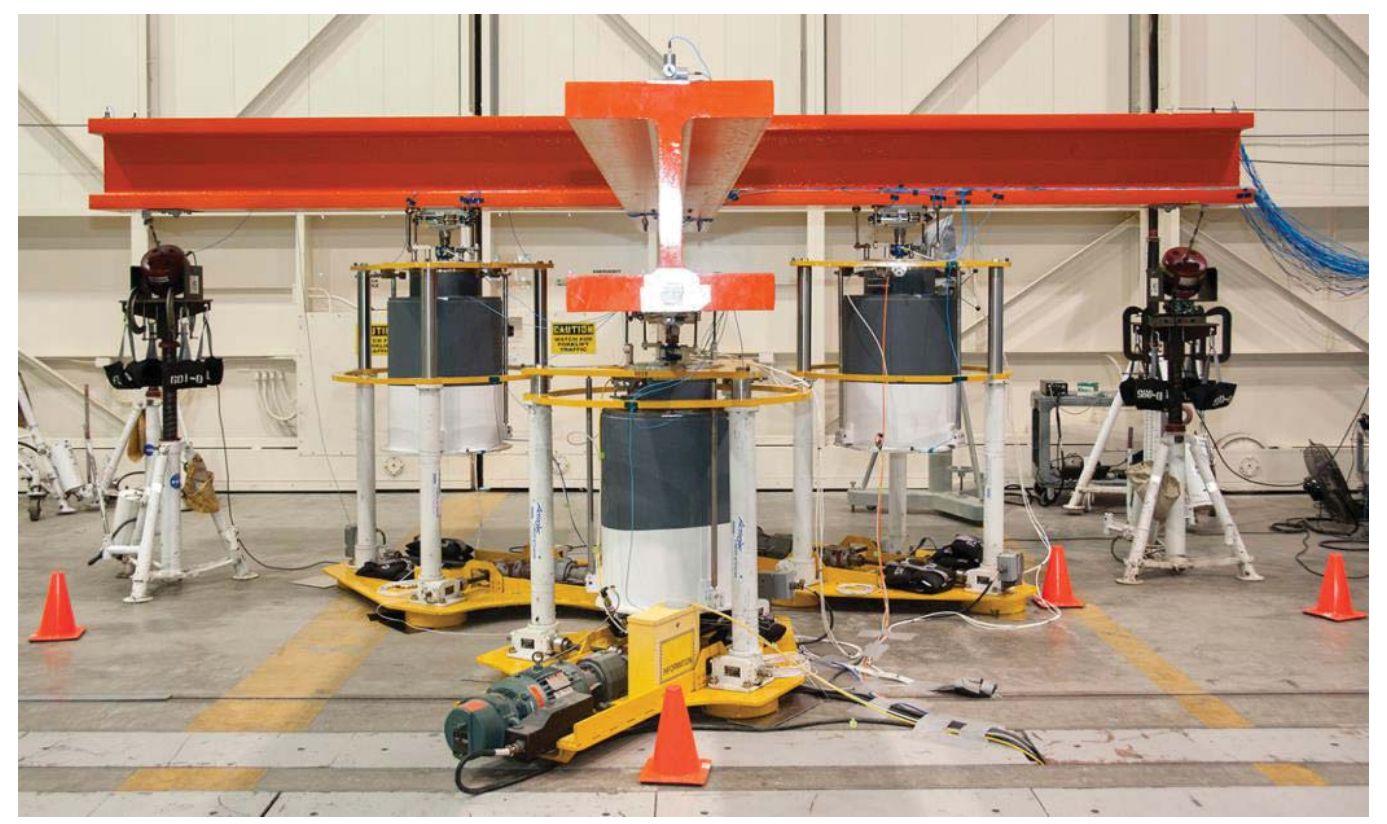

Figure 14. The iron bird undergoing DIM testing on soft supports.

\section{Results}

Post-processing tools were used to extract the FRFs from the test data. The FRFs were analyzed using the ATA Engineering IMAT+SignalTM analysis software where "IMAT" stands for "Interface between MATLAB ${ }^{\circledR}$, Analysis, and Test." 


\subsection{Dynamic Inertia Measurement Analysis}

The PSMIF for the two-shaker random 0- to 100-Hz excitation analysis case is shown in Figure 15. Two PSMIFs are shown: the blue function is the PSMIF for only the DOFs on the iron bird; the green function is the PSMIF for all DOFs, which also includes the DOFs on the 60K3S. While the soft-suspension modes in the frequency range of 10 to $17 \mathrm{~Hz}$ are clearly seen in the PSMIF of all DOFs, they are localized modes of the soft supports and have little response in the iron bird DOFs. The rigid body modes of the iron bird on the soft supports are at $2 \mathrm{~Hz}$ and below, and the flexible modes are above $18 \mathrm{~Hz}$, which is sufficient separation for estimating the inertia properties in this frequency range. The existence of the soft-suspension modes starting at $10 \mathrm{~Hz}$ and becoming prominent at $12 \mathrm{~Hz}$, however, limited the frequency range over which the DIM calculations were performed. Two frequency ranges were analyzed and evaluated to determine the effects of frequency range on DIM analysis results.

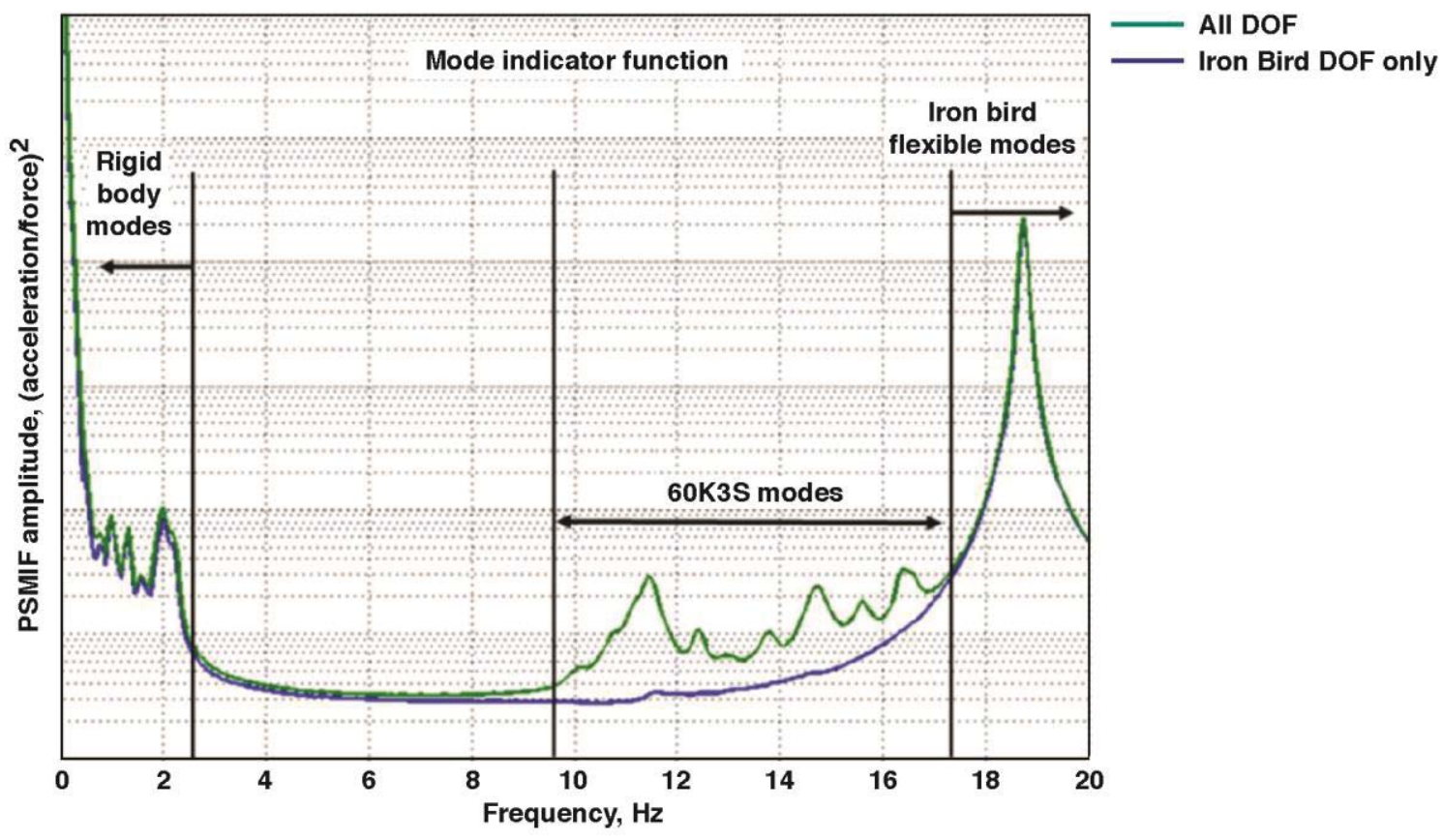

Figure 15. Power spectral mode indicator function for the two-shaker random 0 - to $100-\mathrm{Hz}$ excitation analysis case.

\subsection{Comparison of Seismic and GVT T333B (PCB Piezotronics, Inc.) Accelerometers}

One objective of the DIM test was to determine whether typical GVT accelerometers would be sufficient for accurate DIM analysis or if higher sensitivity seismic accelerometers would be required. The DIM analysis cases were repeated and compared using seismic accelerometers (DIM analysis case 1) and typical modal test T333B (PCB Piezotronics, Inc.) accelerometers (DIM analysis case 4). A method of evaluating the error in DIM calculations is to perform a normalized error function calculation.[7] Figure 16 shows the normalized error functions calculated using the seismic accelerometers for DIM analysis case 1. 


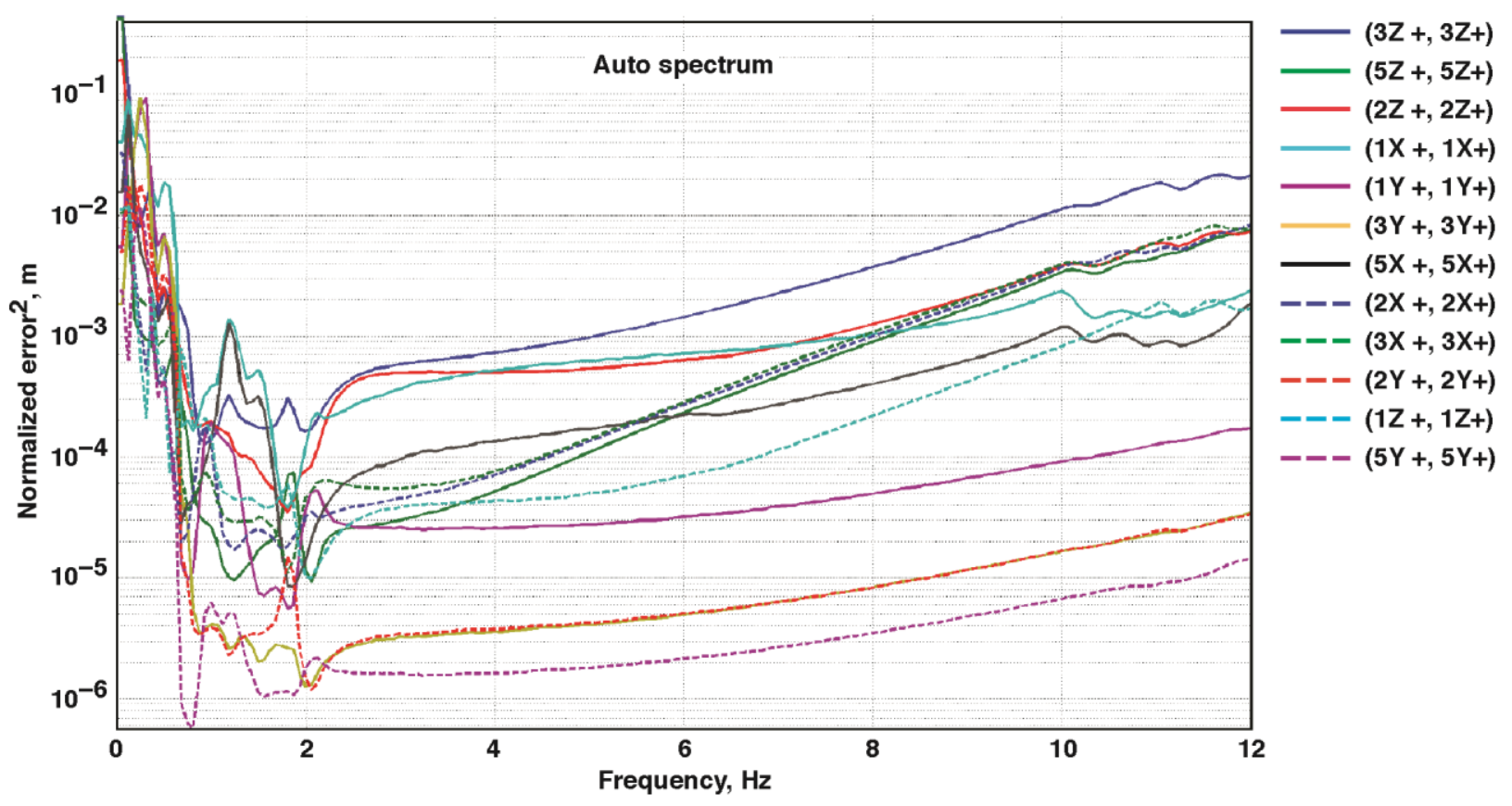

Figure 16. Normalized error functions calculated using the seismic accelerometers for DIM analysis case 1.

No DOFs were consistently and significantly large enough for all test cases to warrant removing them from the mass properties calculations. Figure 17 shows the normalized error functions for DIM analysis case 4 using T333B (PCB Piezotronics, Inc.) GVT accelerometers. As expected, the overall mass properties results from the seismic accelerometers were consistently more in agreement with analytical predictions due to the lower noise floor than that of the T333B (PCB Piezotronics, Inc.) GVT accelerometers. The seismic accelerometers were thought to be required because of their higher sensitivity. The higher sensitivity creates a lower noise floor, which produces acquisition of cleaner data. The cleaner data lessen the variation in the results when compared to the T333B (PCB Piezotronics, Inc.) accelerometers.

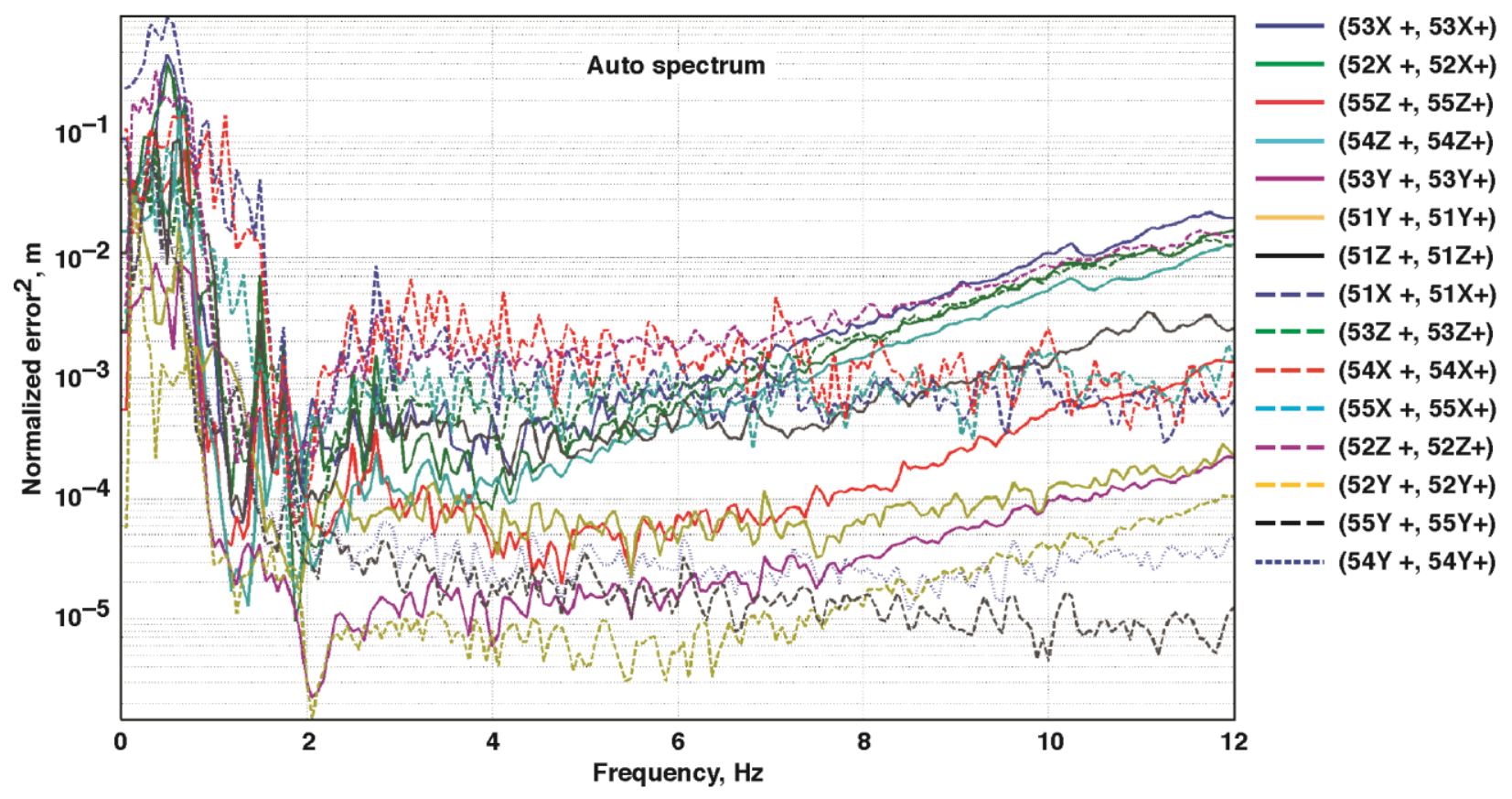

Figure 17. Normalized error functions using the GVT accelerometers for DIM analysis case 4. 


\subsection{Dynamic Inertia Measurement Results}

The computed mass, MOI, POI, and CG values are plotted as a function of frequency for DIM analysis case 1 in Figure 18 for a 2- to $12-\mathrm{Hz}$ DIM analysis. The mass, $\mathrm{X}_{\mathrm{CG}}$ and $\mathrm{Z}_{\mathrm{CG}}$, three MOIs, and $\mathrm{I}_{\mathrm{xz}}$ functions are relatively flat from $2 \mathrm{~Hz}$ to $12 \mathrm{~Hz}$. The $\mathrm{Y}_{\mathrm{CG}}, \mathrm{I}_{\mathrm{xy}}$, and $\mathrm{I}_{\mathrm{yz}}$ functions exhibit greater fluctuations, but since these values are nominally zero and the estimated values are very small compared to the other CG and POI values, these fluctuations are to be expected.

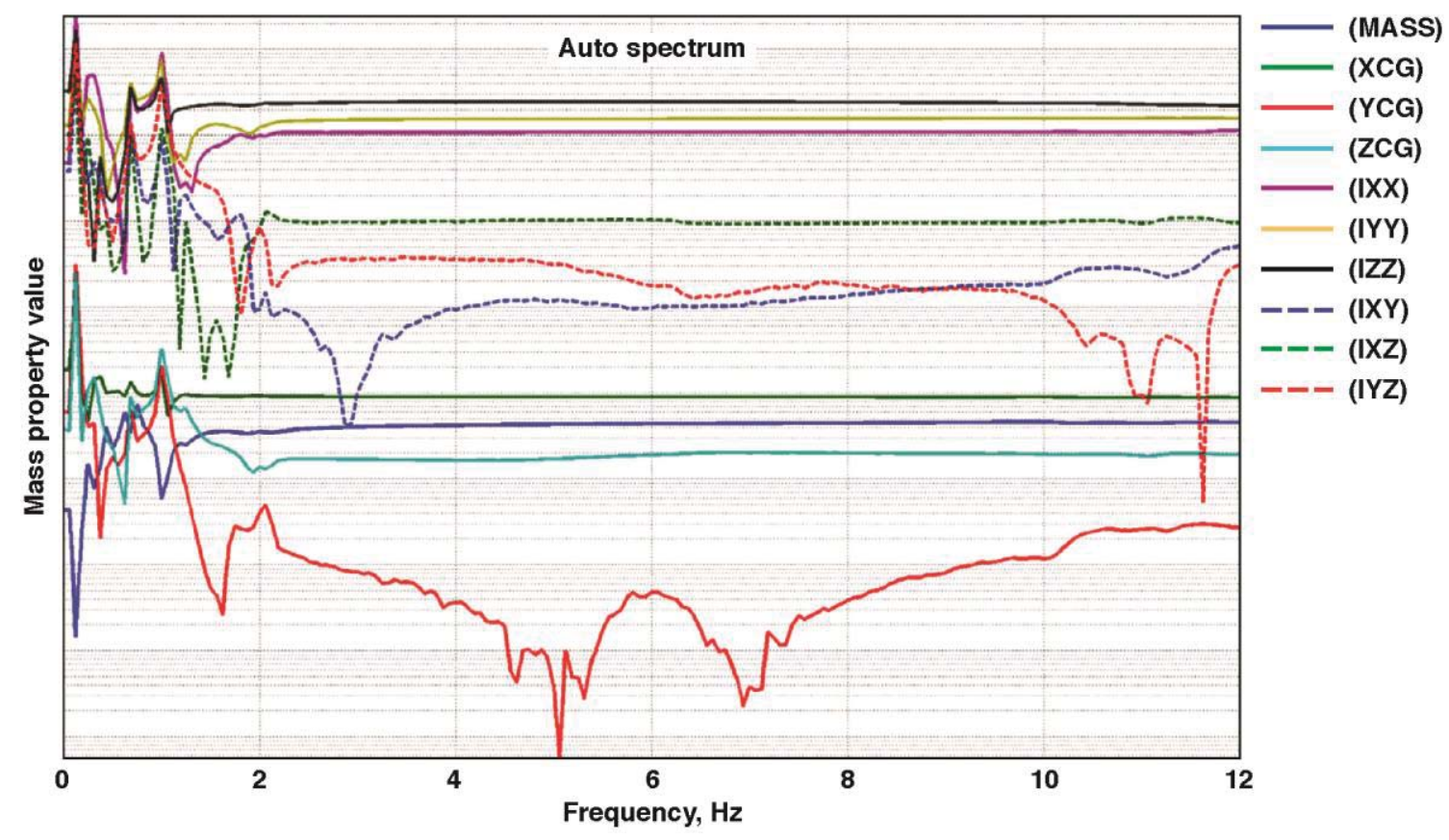

Figure 18. Computed mass properties for DIM analysis case 1.

The mass properties were compared for all DIM analysis cases to determine the ideal frequency band within which to compute average values. From examination of the mass property functions, the 2- to $12-\mathrm{Hz}$ frequency band was fairly flat for all nonzero properties. A second smaller frequency band of 8 to $10 \mathrm{~Hz}$ was also used for DIM processing, as this seemed to be the most consistent region over all of the analysis cases. In general, this smaller 8- to $10-\mathrm{Hz}$ frequency range produced slightly larger mass properties results that were slightly larger than the results produced by the DIM analysis of the 2- to 12-Hz band.

Several parameters of the DIM analyses were varied during testing to investigate which produce the more accurate results. The 3-DOF force transducer provided a measurement for the excitation force in all three translational directions, which included the off-axis components of the input force. In the results presented above for the DIM analysis cases, the off-axis forces measured by the 3-DOF excitation force transducer were treated as additional reaction forces in the inertia calculations. For the two-shaker configurations, however, one of the inputs was measured with a single-axis force transducer because only one 3-DOF force transducer was available. To evaluate their effect on the computed mass properties, two DIM analysis cases were processed excluding the off-axis reaction forces. The two DIM analysis cases studied were the 0 - to $100-\mathrm{Hz}$ random excitation with seismic accelerometers for a single shaker (analysis case 1) and for two shakers (analysis case 7). The mass properties calculations for both cases are across the smaller frequency range of 8 to $10 \mathrm{~Hz}$. The results for the two DIM analysis cases with and without the off-axis forces are listed in Table 6. For both DIM analysis cases, the computed mass was less when not using the off-axis forces. For DIM analysis case 7, however, in which only one shaker had measured off-axis force, the MOIs increased slightly and were closer to DIM analysis case 1. Further study is recommended of the effects of the off-axis forces. 
Table 6. Comparison of mass properties using DIM with and without off-axis forces.

\begin{tabular}{|c|c|c|c|c|c|c|c|c|c|c|c|c|c|c|c|c|c|}
\hline \multirow[b]{2}{*}{ Analysis } & \multicolumn{17}{|c|}{8 -to $10-\mathrm{Hz}$ frequency range } \\
\hline & $\begin{array}{c}\text { MASS, } \\
\mathrm{kg}\end{array}$ & $\begin{array}{l}\text { Mass, } \\
\text { \% error }\end{array}$ & $\begin{array}{c}\mathrm{X}_{\mathrm{CG}}, \\
\mathrm{m}\end{array}$ & $\begin{array}{c}\mathrm{X}_{\mathrm{CG}}, \\
\% \text { error }\end{array}$ & $\begin{array}{c}\mathrm{Y}_{\mathrm{CG}} \\
\mathrm{m}\end{array}$ & $\begin{array}{c}\mathrm{Z}_{\mathrm{CG}}, \\
\mathrm{m}\end{array}$ & $\begin{array}{c}Z_{\mathrm{CG}}, \\
\% \text { error }\end{array}$ & $\begin{array}{c}\mathrm{I}_{\mathrm{XX}} \\
\mathrm{kg}^{*} \mathrm{~m}^{2}\end{array}$ & $\begin{array}{c}\mathrm{I}_{\mathrm{XX}}, \\
\% \text { error }\end{array}$ & $\begin{array}{c}\mathrm{I}_{\mathrm{YY}}, \\
\mathrm{kg}^{*} \mathrm{~m}^{2}\end{array}$ & \begin{tabular}{|c|}
$\mathrm{I}_{\mathrm{YY}}$, \\
$\%$ \\
error \\
\end{tabular} & $\begin{array}{c}\mathrm{I}_{\mathrm{zz}} \\
\mathrm{kg}^{*} \mathrm{~m}^{2}\end{array}$ & $\begin{array}{c}\mathrm{I}_{\mathrm{ZZ}}, \\
\% \text { error }\end{array}$ & $\begin{array}{c}\mathrm{I}_{\mathrm{XY}} \\
\mathrm{kg}^{*} \mathrm{~m}^{2}\end{array}$ & $\begin{array}{c}\mathrm{I}_{\mathrm{XZ}} \\
\mathrm{kg}^{*} \mathrm{~m}^{2}\end{array}$ & $\begin{array}{c}\mathrm{I}_{\mathrm{XZ}}, \\
\% \text { error }\end{array}$ & $\begin{array}{c}\mathrm{I}_{\mathrm{YZ}}, \\
\mathrm{kg}^{*} \mathrm{~m}^{2}\end{array}$ \\
\hline 1 & 7,981 & $3.40 \%$ & 2.273 & $-0.60 \%$ & $0 . \overline{-}$ & 0.485 & $2.00 \%$ & 12349.4 & $-2.70 \%$ & 17616.9 & $2.30 \%$ & 26952.1 & $-5.50 \%$ & -172.7 & -1106.2 & $-21.00 \%$ & 155.1 \\
\hline $\begin{array}{l}1 \text { (no off-axis } \\
\text { force) }\end{array}$ & 7,624 & $-1.20 \%$ & 2.278 & $-0.30 \%$ & \begin{tabular}{|c|}
- \\
0.0051 \\
\end{tabular} & 0.462 & $-2.70 \%$ & 12290.9 & $-3.30 \%$ & 17470.6 & $1.50 \%$ & 26981.4 & $-5.30 \%$ & -117.1 & -1123.7 & $-19.80 \%$ & 149.2 \\
\hline 7 & 7,568 & $-1.90 \%$ & 2.271 & $-0.70 \%$ & 0.0737 & 0.259 & $-45.30 \%$ & 8896.3 & \begin{tabular}{|c|}
- \\
30.00 \\
$\%$ \\
\end{tabular} & 17060.9 & $\begin{array}{c}- \\
0.80 \%\end{array}$ & 22240.6 & $\begin{array}{c}22.00 \\
\%\end{array}$ & -1144.2 & 2838.6 & $\begin{array}{c}- \\
302.80 \%\end{array}$ & $\begin{array}{c}- \\
1267.1\end{array}$ \\
\hline $\begin{array}{l}7 \text { (no off-axis } \\
\text { force) }\end{array}$ & 7,214 & $-6.50 \%$ & 2.283 & $-0.10 \%$ & 0.0432 & 0.320 & $-32.50 \%$ & 9949.8 & \begin{tabular}{|c|}
- \\
21.70 \\
$\%$
\end{tabular} & 17441.3 & $1.40 \%$ & 24815.9 & $\begin{array}{c}12.90 \\
\%\end{array}$ & -468.2 & 1387.1 & $199.20 \%$ & -5.9 \\
\hline
\end{tabular}

Table 7 summarizes the mass properties calculation across the 2- to $12-\mathrm{Hz}$ frequency range for all DIM analysis cases. These cases are calculated using the off-axis forces measured by the 3-DOF force transducer.

Table 7. Summary of mass properties using DIM for the 2- to 12-Hz frequency range.

\begin{tabular}{|c|c|c|c|c|c|c|c|c|c|c|c|c|c|c|c|c|c|}
\hline & \multicolumn{17}{|c|}{ 2- to $12-\mathrm{Hz}$ frequency range } \\
\hline $\begin{array}{l}\text { Analysis } \\
\text { case }\end{array}$ & $\begin{array}{c}\text { MASS, } \\
\mathrm{kg}\end{array}$ & $\begin{array}{c}\text { Mass, } \\
\% \text { error }\end{array}$ & \begin{tabular}{|c|}
$\mathrm{X}_{\mathrm{CG}}$, \\
$\mathrm{m}$
\end{tabular} & $\begin{array}{c}\mathrm{X}_{\mathrm{CG}}, \\
\% \text { error } \\
\end{array}$ & \begin{tabular}{|c|}
$\mathrm{Y}_{\mathrm{CG}}$, \\
$\mathrm{m}$
\end{tabular} & \begin{tabular}{|c|}
$\mathrm{Z}_{\mathrm{CG}}$ \\
$\mathrm{m}$
\end{tabular} & $\begin{array}{c}Z_{\mathrm{CG}}, \\
\% \text { error } \\
\end{array}$ & $\begin{array}{c}\mathrm{I}_{\mathrm{XX}}, \\
\mathrm{kg}^{*} \mathrm{~m}^{2}\end{array}$ & $\begin{array}{c}\mathrm{I}_{\mathrm{XX}}, \\
\% \text { error } \\
\end{array}$ & \begin{tabular}{|c|}
$\mathrm{I}_{\mathrm{YY}}$, \\
$\mathrm{kg}^{*} \mathrm{~m}^{2}$ \\
\end{tabular} & $\begin{array}{c}\mathrm{I}_{\mathrm{YY}}, \\
\% \text { error } \\
\end{array}$ & $\begin{array}{c}\mathrm{I}_{\mathrm{zZ}} \\
\mathrm{kg}^{*} \mathrm{~m}^{2} \\
\end{array}$ & $\begin{array}{c}\mathrm{I}_{\mathrm{ZZ}} \\
\% \text { error } \\
\end{array}$ & $\begin{array}{c}\mathrm{I}_{\mathrm{XY}} \\
\mathrm{kg}^{*} \mathrm{~m}^{2} \\
\end{array}$ & $\begin{array}{c}\mathrm{I}_{\mathrm{XZ}} \\
\mathrm{kg}^{*} \mathrm{~m}^{2} \\
\end{array}$ & $\begin{array}{c}\mathrm{I}_{\mathrm{XZ}}, \\
\% \text { error } \\
\end{array}$ & $\begin{array}{c}\mathrm{I}_{\mathrm{YZ}} \\
\mathrm{kg}^{*} \mathrm{~m}^{2} \\
\end{array}$ \\
\hline 1 & 7,623 & $-1.20 \%$ & 2.278 & $-0.30 \%$ & -0.005 & 0.462 & $-2.60 \%$ & 12290.9 & $-3.20 \%$ & 17470.6 & $1.50 \%$ & 27010.7 & $-5.20 \%$ & -120.0 & -1120.8 & $-19.90 \%$ & 187.3 \\
\hline 2 & 7,631 & $.10 \%$ & 2.278 & $.30 \%$ & .010 & 0.472 & $0.70 \%$ & 12290.9 & $-3.20 \%$ & 17382.8 & $1.00 \%$ & 27010.7 & $-5.20 \%$ & -155.1 & -1114.9 & $-20.30 \%$ & 228.3 \\
\hline 3 & 7,600 & $.50 \%$ & 2.278 & $-0.40 \%$ & -0.013 & 0.470 & $-1.00 \%$ & 12290.9 & $-3.30 \%$ & 17382.8 & $1.00 \%$ & 27010.7 & $-5.20 \%$ & -155.1 & -1094.5 & $-21.90 \%$ & 275.1 \\
\hline 4 & 474 & $3.10 \%$ & 2.299 & $60 \%$ & 0.028 & 0.445 & $-6.20 \%$ & 12203.1 & $3.90 \%$ & 16680.5 & $3.10 \%$ & 27537.4 & $-3.40 \%$ & -90.7 & -951.1 & $-32.10 \%$ & -275 \\
\hline 5 & 7,523 & $-2.50 \%$ & 2.299 & $0.50 \%$ & 0.025 & 0.460 & $-3.40 \%$ & 12203.1 & $-3.90 \%$ & 16622.0 & $-3.30 \%$ & 27537.4 & $-3.40 \%$ & -114.1 & -942.3 & $-32.70 \%$ & -245.8 \\
\hline 6 & 7,509 & $-2.70 \%$ & 2.299 & $0.50 \%$ & 0.023 & 0.457 & $-3.70 \%$ & 12203.1 & $-3.90 \%$ & 16651.2 & $-3.20 \%$ & 27508.2 & $-3.50 \%$ & -111.2 & -924.7 & $-33.80 \%$ & -207.8 \\
\hline 7 & 7,209 & $-6.60 \%$ & 2.278 & $\%$ & 0.064 & 0.297 & $-37.70 \%$ & 9627.9 & $-24.30 \%$ & 17207.2 & $-0.10 \%$ & 24289.1 & -14 & -640.9 & 1630.0 & $-216.60 \%$ & -298.5 \\
\hline 8 & 7,316 & $-5.20 \%$ & 2.271 & $-0.70 \%$ & 0.066 & 0.335 & $-29.40 \%$ & 10213.1 & $-19.60 \%$ & 17265.8 & $0.30 \%$ & 23703.8 & -16 & -693.6 & 1586.1 & $-213.40 \%$ & -418.5 \\
\hline 9 & 7,119 & $-7.70 \%$ & 2.291 & $0.20 \%$ & 0.046 & 0.328 & $-30.90 \%$ & 9598.6 & $-24.40 \%$ & 17265.8 & $0.40 \%$ & 23879.4 & -16 & -772.6 & 1808.5 & -229 & -550 \\
\hline 10 & 7,263 & $-5.90 \%$ & 2.299 & $0.60 \%$ & 0.056 & 0.353 & $-25.60 \%$ & 10096.1 & $-20.50 \%$ & 16534.2 & $-3.80 \%$ & 2619 & $-8.10 \%$ & -421.4 & 719.9 & $-151.40 \%$ & -485 \\
\hline 11 & 6,562 & $-15.00 \%$ & 2.296 & $0.50 \%$ & 0.038 & 0.462 & $-2.40 \%$ & 11003.3 & $-13.30 \%$ & 16651.2 & $-3.20 \%$ & 26337.6 & $-7.60 \%$ & -301.4 & 248.7 & $-117.80 \%$ & -310.2 \\
\hline 12 & 146 & $-7.40 \%$ & 2.309 & $1.00 \%$ & 0.043 & 0.386 & $-18.60 \%$ & 10096.1 & $-20.50 \%$ & 16387.8 & $-4.80 \%$ & 25547.5 & $-10.40 \%$ & -561.9 & 860.4 & $-161.50 \%$ & $-834 .($ \\
\hline
\end{tabular}

Table 8 summarizes the mass properties calculation across the smaller 8 - to $10-\mathrm{Hz}$ frequency range for all DIM analysis cases. These cases are also calculated using the off-axis forces measured by the 3-DOF force transducer. 
Table 8. Summary of mass properties using DIM for the 8- to 10-Hz frequency range.

\begin{tabular}{|c|c|c|c|c|c|c|c|c|c|c|c|c|c|c|c|c|c|}
\hline & \multicolumn{17}{|c|}{ 8- to $10-\mathrm{Hz}$ frequency range } \\
\hline $\begin{array}{l}\text { Analysis } \\
\text { case }\end{array}$ & $\begin{array}{c}\text { MASS, } \\
\mathrm{kg} \\
\end{array}$ & $\begin{array}{l}\text { Mass, } \\
\% \text { error }\end{array}$ & $\begin{array}{c}\mathrm{X}_{\mathrm{CG}}, \\
\mathrm{m}\end{array}$ & \begin{tabular}{|c|}
$\mathrm{X}_{\mathrm{CG}}$, \\
$\%$ error
\end{tabular} & $\begin{array}{c}Y_{\mathrm{CG}}, \\
\mathrm{m}\end{array}$ & \begin{tabular}{|c|}
$Z_{\mathrm{CG}}$ \\
$\mathrm{m}$
\end{tabular} & \begin{tabular}{|c|}
$Z_{\mathrm{CG}}$, \\
$\%$ error \\
\end{tabular} & $\begin{array}{c}\mathrm{I}_{\mathrm{Xx}}, \\
\mathrm{kg}^{*} \mathrm{~m}^{2} \\
\end{array}$ & $\begin{array}{c}\mathrm{I}_{\mathrm{XX}}, \\
\% \text { error }\end{array}$ & $\begin{array}{c}\mathrm{I}_{\mathrm{YY}}, \\
\mathrm{kg}^{*} \mathrm{~m}^{2} \\
\end{array}$ & \begin{tabular}{|c|}
$\mathrm{I}_{\mathrm{YY}}$, \\
$\%$ error
\end{tabular} & $\begin{array}{c}\mathrm{I}_{\mathrm{ZZ}}, \\
\mathrm{kg}^{*} \mathrm{~m}^{2}\end{array}$ & \begin{tabular}{|c|} 
Izz, \\
$\%$ error \\
\end{tabular} & $\begin{array}{c}\mathrm{I}_{\mathrm{XY}}, \\
\mathrm{kg}^{*} \mathrm{~m}^{2}\end{array}$ & $\begin{array}{c}\mathrm{I} X \mathrm{XZ} \\
\mathrm{kg}^{*} \mathrm{~m}^{2} \\
\end{array}$ & $\begin{array}{c}\mathrm{I}_{\mathrm{XZ}}, \\
\% \text { error } \\
\end{array}$ & $\begin{array}{c}\mathrm{I}_{\mathrm{YZ}}, \\
\mathrm{kg}^{*} \mathrm{~m}^{2}\end{array}$ \\
\hline 1 & 7,981 & $3.40 \%$ & 2.273 & $-0.60 \%$ & -0.018 & 0.485 & $2.00 \%$ & 12349.4 & $-2.70 \%$ & 17616.9 & $2.30 \%$ & 26952.1 & $-5.50 \%$ & -172.7 & -1106.2 & $-21.00 \%$ & 155.2 \\
\hline 2 & 7,979 & $3.40 \%$ & 2.273 & $-0.50 \%$ & -0.023 & 0.500 & $5.20 \%$ & 12349.4 & $-2.70 \%$ & 17558.4 & $2.00 \%$ & 26981.4 & $-5.40 \%$ & -187.3 & -1082.8 & $-22.70 \%$ & 178.5 \\
\hline 3 & 7,985 & $3.50 \%$ & 2.276 & $-0.40 \%$ & -0.023 & 0.500 & $5.30 \%$ & 12349.4 & $-2.70 \%$ & 17558.4 & $2.10 \%$ & 27010.6 & $-5.20 \%$ & -172.7 & -1091.6 & $-21.90 \%$ & 298.5 \\
\hline 4 & 7,796 & $1.00 \%$ & 2.299 & $0.60 \%$ & 0.033 & 0.457 & $-3.80 \%$ & 12290.9 & $-3.30 \%$ & 16856.1 & $-2.00 \%$ & 27888.6 & $-2.10 \%$ & -143.4 & -916.0 & $-34.50 \%$ & -351.2 \\
\hline 5 & 7,811 & $1.20 \%$ & 2.299 & $0.60 \%$ & 0.028 & 0.480 & $1.30 \%$ & 12261.6 & $-3.50 \%$ & 16826.8 & $-2.20 \%$ & 27888.6 & $-2.10 \%$ & -143.4 & -904.3 & $-35.30 \%$ & -310.2 \\
\hline 6 & 7,815 & $1.30 \%$ & 2.301 & $0.60 \%$ & 0.025 & 0.483 & $1.60 \%$ & 12261.6 & $-3.50 \%$ & 16856.1 & $-2.10 \%$ & 27917.9 & $-2.00 \%$ & -125.8 & -910.1 & $-35.00 \%$ & -219.5 \\
\hline 7 & 7,568 & $-1.90 \%$ & 2.271 & $-0.70 \%$ & 0.074 & 0.259 & $-45.30 \%$ & 8896.3 & $-30.00 \%$ & 17060.9 & $-0.80 \%$ & 22240.6 & $-22.00 \%$ & -1144.2 & 2838.6 & $-302.80 \%$ & -1267.1 \\
\hline 8 & 7,616 & $-1.30 \%$ & 2.268 & $-0.80 \%$ & 0.061 & 0.315 & $-33.70 \%$ & 10330.2 & $-18.50 \%$ & 18231.5 & $6.00 \%$ & 24757.3 & $-13.10 \%$ & -263.4 & 1267.1 & $-190.60 \%$ & 377.5 \\
\hline 9 & 7,554 & $-2.10 \%$ & 2.278 & $-0.30 \%$ & -0.003 & 0.368 & $-22.20 \%$ & 10008.3 & $-21.20 \%$ & 17792.5 & $3.40 \%$ & 23089.3 & $-19.00 \%$ & -737.5 & 2112.9 & $-251.00 \%$ & -860.4 \\
\hline 10 & 7,527 & $-2.50 \%$ & 2.306 & $0.90 \%$ & 0.061 & 0.345 & $-27.20 \%$ & 9569.3 & $-24.60 \%$ & 16709.7 & $-2.90 \%$ & 25108.5 & $-11.90 \%$ & -784.3 & 1451.5 & $-203.70 \%$ & -1182.3 \\
\hline 11 & 7,058 & -8.50 & 2.311 & $1.10 \%$ & 0.038 & 0.439 & $-7.60 \%$ & 11647.1 & $-8.30 \%$ & 17909.6 & $4.10 \%$ & 29820.0 & $4.60 \%$ & 529.7 & -1372.5 & $-1.80 \%$ & 1293.5 \\
\hline 12 & 7,337 & $-4.90^{\circ}$ & 2.316 & $1.30 \%$ & 0.000 & 0.457 & $-3.40 \%$ & 10944.7 & $-13.70 \%$ & 17178.0 & $-0.20 \%$ & 26688.8 & $-6.30 \%$ & -105.4 & 58.5 & $-104.20 \%$ & -439.0 \\
\hline
\end{tabular}

\subsection{Comparison of Results from Different Methods}

Table 9 summarizes the results from analytical, pendulum swings, and DIM methods to find mass properties. Case 1 of the DIM method was used for comparison. The symmetrical geometry of the iron bird made the $\mathrm{I}_{\mathrm{xy}}$ and $\mathrm{I}_{\mathrm{yz}}$ POI negligible; they were not tested.

Table 9. Summary of mass properties calculations derived by three different methods.

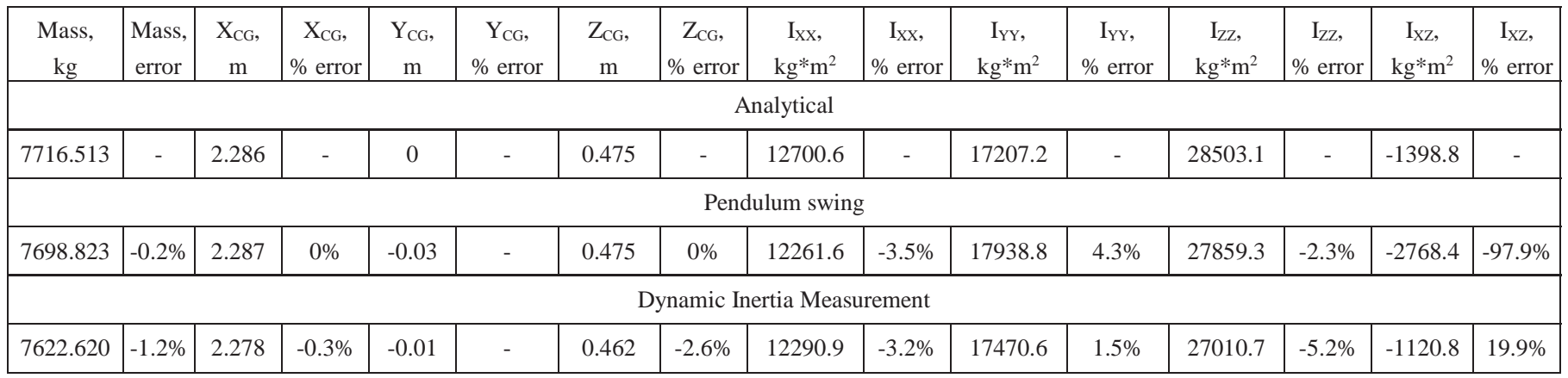

The DIM method yielded results that matched within approximately 5 percent of the analytical iron bird mass, CG, and MOI. The $\mathrm{I}_{\mathrm{xz}}$ POI did not match as well, having errors exceeding 20 percent, however, the DIM $\mathrm{I}_{\mathrm{xz}}$ results were still better than the 98-percent error from the pendulum-based testing results due to test setup limitations (that is, shallow tilt angle).

The results for the DIM method were in good agreement with the analytical predictions, but the DIM method also demonstrated other benefits. The DIM method enabled more of the mass properties to be measured using less hardware, fewer test configurations, and less testing time. The time, resources, and labor required to execute both the pendulum oscillation and the DIM methods were noted to compare these two methods in these aspects.

Conventional pendulum testing methods require orienting the test article in several different configurations. The measurement of weight and CG is required for MOI testing, which calls for a different setup than that used for MOI. The MOIs each require a different orientation (that is, test setup) for each axis: $\mathrm{I}_{\mathrm{xx}}, \mathrm{I}_{\mathrm{yy}}, \mathrm{I}_{\mathrm{zz}}$, and $\mathrm{I}_{\mathrm{xz}}$. Additionally, any fixtures attached to the test article as part of the setup must also be tested to measure their contribution to the total measured inertia. Without considering delays, and including test setup and teardown, the measurement of the mass properties using conventional methods required approximately 30 days. 
The DIM test requires setup and teardown times similar to that required for GVT, but with the additional DIM sensors the DIM and GVT data can be acquired simultaneously. As well, the DIM method can be executed using a single vehicle configuration and without extra fixtures. No additional data are needed for this method, and the DIM method has been shown to be able to provide the full set of mass properties. Without considering delays and including test setup and teardown, the measurement of the mass properties using the DIM method required approximately 15 days.

A similar comparison can be made for the cost associated with each method. An appreciable amount of the equipment that is required to execute the DIM method consists of equipment that is already used for execution of GVTs. A GVT requires accelerometers, soft-support systems, shakers, and force transducers. A GVT may be expanded to encompass a DIM test by adding 6-DOF force sensors, a 3-DOF force transducer, and seismic accelerometers, which are currently thought to be required for successful and more accurate DIM calculations. All aircraft and flight test experiments call for a GVT as part of the airworthiness process at some point in the project life cycle. The additional time necessary to set up and tear down for a DIM test is minimal, since most of the involved activities are already required when performing a GVT. A GVT can, therefore, be expanded to a DIM test without causing significant inconvenience or schedule addition and can provide more of the mass properties than could be acquired using the pendulum methods. As well, conventional pendulum methods require massive fixtures, extensive lift procedures and reviews, and more testing time, but only provide a limited number of the mass properties.

It is recognized that state-of-the-art DIM test execution requires equipment that is more expensive than the equipment required for the pendulum tests. The 6-DOF force sensors are custom-designed, one-of-a-kind equipment, and as a result necessitate high recurring costs for calibration. The seismic accelerometers are currently thought to be required because of the low noise floor they exhibit, and the 3-DOF excitation force transducer is considered required because the off-axis forces are used as additional reaction forces in the DIM calculations. These are more specialized types of equipment than the typical GVT accelerometers, and as such are more expensive and also necessitate more costly calibration procedures. The laser tracker is a high-precision measurement instrument and is also considered to be expensive. Most of these pieces of equipment, however, are considered to be one-time costs, and with further development the DIM method may show promise in becoming more feasible.

\section{Recommendations and Considerations}

This iron bird testing series was a successful exercise; however, the DIM method is not yet a fully mature technology for large aerospace vehicles. ATA Engineering provided the following list of recommendations and considerations for future DIM method tests, DIM processing, and DIM theory to further advance the technology readiness level (TRL) of the DIM method on large aerospace vehicles.

\subsection{Testing Recommendations and Considerations}

1. Retest with the iron bird supported on bladder-type air springs instead of the 60K3S system for this test. Using this other type of soft support should eliminate the cluster of modes in the 5- to 8-Hz frequency range and give a broader frequency range over which to estimate the inertia properties.

2. Predict MOI perturbation by adding a mass with known inertia properties to the structure.

\subsection{Processing Recommendations and Considerations}

1. Process the measurements assuming that the accelerometers were mounted in the global coordinate system.

2. Investigate how many accelerometers are sufficient to produce accurate inertia results.

3. Evaluate whether 3-DOF reaction forces are sufficient or 6-DOF reaction forces are necessary.

4. Reformulate the inertia equations for known terms (for example, mass, 2 of 3 CG coordinates).

5. Develop a non-subjective procedure to select the "flat spot" in the inertia functions.

6. Develop and explore uncertainty analysis methods for DIM calculations such as a Monte Carlo or Cramer-Rao bounds.

7. Implement spatial filtering with the ATA Engineering IMAT+Signal' ${ }^{\mathrm{TM}}$ spVIEW ${ }^{\mathrm{TM}}$ user tools.

\subsection{Basic Theory Recommendations and Considerations}

1. Perform analysis or modeling to better understand the effects of force path and to explain more completely the differences of exciting on the structure and exciting through the force sensors.

2. Investigate the influence of gravity at low frequency. Is the calibration of the 6-DOF force sensors dependent on the orientation of the calibration mass in the gravitation field? It is known that the output of sensors depends upon orientation, but the current implementation does not compensate for gravity. 


\subsection{Additional Recommendations}

1. Evaluate the effects of the 3-DOF force transducer off-axis reaction forces on the accuracy of the computed mass properties.

2. Investigate the required redundancy for the excitation of the six rigid body modes in relation to the typical multiple-shaker configurations used during GVT.

\section{Conclusions}

The Dynamic Inertia Measurement (DIM) method shows promise for mass properties testing applications involving large aerospace vehicles. There were sources of error that required mitigation; for example, the soft-support system introduced modes into the test data. As well, the DIM method was found to be sensitive to different shaker configurations and test setups. Several recommendations were therefore made with regard to the method of DIM testing.

Performing the DIM method on the "iron bird" test article advanced the maturity level of the method toward future use on full-scale aerospace vehicles. The next step in the maturation of the DIM method would be to apply the technique to a full-scale aerospace vehicle.

Conventional pendulum-based mass properties testing was performed to compare results and level of effort with the DIM method. The pendulum methods created a variety of operational challenges. Several lift procedures and reviews were required to move the iron bird test article into the pendulum-testing configuration due to the safety-critical nature of the setup, and the design of the pendulum test setup itself had many shortcomings. For example, design flaws in the test hardware introduced friction into the test setup that created a frequency shift and deteriorated the quality of the data. In spite of these challenges, usable data were collected and used to estimate mass properties.

The iron bird test article was supported on three soft supports that simulated free-free boundary conditions. The rigid body modes were below $2 \mathrm{~Hz}$, and the first flexible mode was above $18 \mathrm{~Hz}$, which was sufficient separation for the DIM method; however, there was a cluster of soft-support modes in the 10- to $17-\mathrm{Hz}$ frequency range. These modes were localized suspension modes having little effect on the calculated inertia functions below $12 \mathrm{~Hz}$. This configuration allowed a maximum 2- to $12-\mathrm{Hz}$ frequency band from which to estimate inertia and center of gravity values. The results were fairly consistent across the six single-shaker test cases, and the relative error compared to analytical values was typically only a few percent, except for the one non-zero product of inertia. The results for the six skewed, double-shaker test cases, however, exhibited greater relative error and larger variance among the test runs. Therefore, in this iron bird case, single-shaker configurations provided the best results.

The DIM mass properties testing method requires expensive sensors and equipment. Fortunately, much of the necessary equipment is already available if ground vibration testing has been performed. Additionally, performing the DIM test can simultaneously provide the same modal characteristics data used for ground vibration testing analysis. After comparing the labor and time needed to perform each test, the DIM test was determined to be capable of experimentally determining mass properties twice as fast as the conventional pendulum method. In addition, the conventional pendulum method contains much higher schedule and vehicle risk, requires more procedural reviews and multiple pieces of specialized hardware and interface frames, and multiple testing configurations. The DIM method, with further development, may prove to be a more efficient approach to estimating the mass properties of a large aerospace vehicle.

\section{Acknowledgements}

The authors thank the NASA Aeronautics Research Mission Directorate Aerosciences Project and Aeronautics Test Program for funding the Dynamic Inertia Measurement research. The authors also thank the testing support personnel at the Flight Loads Laboratory at the Armstrong Flight Research Center for conducting the Dynamic Inertia Measurement and pendulum tests. Special thanks also go to aerospace engineers Bob Clarke and Adam Harding of the Armstrong Flight Research Center for their support and expertise in performing the conventional pendulum mass properties tests.

\section{References}

[1] Toivola, J., Nuutila, O., Comparison of three methods for determining rigid body inertia properties from frequency response functions, Proceedings of the 11th International Modal Analysis Conference, pp. 1126-1132, 1993.

[2] Witter, M. C., Rigid body inertia property estimation using the dynamic inertia method, Master of Science thesis, Department of Mechanical Engineering, University of Cincinnati, 2000.

[3] Lazor, D. R., Considerations for using the dynamic inertia method in estimating rigid body inertia property, Master's of Science thesis, Department of Mechanical Engineering, University of Cincinnati, 2004.

[4] Peterson, W. L., Mass properties measurement in the X-38 project, SAWE paper no. 3325, category 6, 2004.

[5] Stebbins, M. A., Brown, D. L., Rigid body inertia property estimation using a six-axis load cell, Proceedings of the 16th International Modal Analysis Conference, pp. 900-906, 1998.

[6] Gatzwiller, K. B., Witter, M. C., Brown, D. L., A new method for measuring inertial properties, Proceedings of the 18th International Modal Analysis Conference, pp. 1056-1062, 2000. 
[7] Witter, M. C., Brown, D. L., Dillon, M., A new method for RBP estimation - the dynamic inertia method, SAWE paper no. 2461, category no. 6, 1999.

[8] Green, M. W., Measurement of the moments of inertia of full scale airplanes, NACA Technical Note No. $265,1927$.

[9] Miller, M. P., An accurate method of measuring the moments of inertia of airplanes, NACA Technical Note No. 351, 1930.

[10] Miller, M. P., Soule, H. A., Moments of inertia of several airplanes, NACA Technical Note No. 375, 1931.

[11] Soule, H. A., Miller, M. P., The experimental determination of the moments of inertia of airplanes, NACA Report No. 467, 1933.

[12] Turner, H. L., Measurement of the moments of inertia of an airplane by a simplified method, NACA Technical Note 2201, 1950.

[13] Gracey, W., The additional-mass effect of plates as determined by experiments, NACA Report No. 707, 1941.

[14] Fladung, W. A., Napolitano, K. L., Brillhart, R. D., Final report on dynamic inertia measurement method testing, unpublished internal document, ATA Engineering, San Diego, California, 2010.

[15] Cloutier, D., Fladung, W. A., Final report on dynamic inertia measurement method testing on iron bird 2, unpublished internal document, ATA Engineering, San Diego, California, 2013.

[16] Holland J.A., A safe, advanced, adaptable isolation system that eliminates the need for critical lifts, NP-2009-08-02-DFRC, http://www.nasa.gov/pdf/484129main_Soft-Support-TOP.pdf [accessed October 30, 2014]. 